\title{
A review of stochastic dominance methods for poverty
}

\author{
analysis
}

April 26, 2019

\begin{abstract}
Stochastic dominance techniques have been mainly employed in poverty analyses to overcome what it is called the multiplicity of poverty indices problem. Moreover, in the multidimensional context, stochastic dominance techniques capture the possible relationships between the dimensions of poverty as it relies upon their joint distribution, unlike most multidimensional poverty indices, which are only based on marginal distributions. In this paper, we first review the general definition of unidimensional stochastic dominance and its relationship with poverty orderings. Then we focus on the conditions of multivariate stochastic dominance and their relationship with multidimensional poverty orderings, highlighting the additional difficulties that the multivariate setting involves. In both cases we focus our discussion on first and second-order dominance, though some guidelines on higher-order dominance are also mentioned. We also present an overview of some relevant empirical applications of these methods that can be found in the literature in both univariate and multivariate contexts.
\end{abstract}

Keywords: stochastic dominance, poverty orderings, multidimensional poverty

JEL Classification: C10, C30, C39, D31, I32 


\section{Introduction}

Poverty measurement is a key issue from both a social and a research point of view. As a matter of fact, the 2030 Agenda for Sustainable Development, adopted by all United Nations Member States in 2015, set the so-called United Nations Sustainable Development Goals, the first one being: "End poverty in all its forms everywhere". At the EU level, the Europe 2020 strategy, adopted by the European Council in 2010, established five headline targets, one of which is poverty reduction. In this framework, the question arises on how to evaluate whether the poverty has decreased over a certain period of time or whether the poverty is higher or lower in one country than another. In fact, as Ravallion (1992) points out, "the most important reason for measuring poverty is probably not the need for a single number for some place and date, but rather to make a poverty comparison".

To face this task, several proposals have been made in the literature. On one hand, poverty comparisons can be made through indicators that reflect in a summary value the overall level of poverty in a society. This approach has been traditionally based on unidimensional poverty measures that were only focused on income; see Zheng (1997). However, it is already wellrecognized that poverty is multidimensional as it involves not only low incomes, but also deprivations in other aspects, such as health, education or labour; see Kolm (1977), Sen (1985) or Stiglitz et al. (2009). On this point, the United Nations Development Program launched, in 2010, the Multidimensional Poverty Index (MPI) based on the Alkire and Foster (2011) proposal. This index captures the multiple deprivations that poor people experience with respect to health, education and living standards. The EU has also adopted a multidimensional approach to measuring poverty on the basis of an aggregate indicator of 'At Risk of Poverty or social Exclusion' (AROPE) that takes into account relative income poverty, material deprivation and work intensity. The literature on methodological aspects and applications of these and other multivariate poverty indices is enormous; to mention but a few, see Aaberge and Brandolini (2015) and Alkire et al. (2015). 
In spite of its widespread use, the approach based on comparing poverty indicators has several limitations. The first has to do with the robustness of the results to the measure used, since different measures could rank groups differently in terms of poverty. Moreover, in a multidimensional context additional difficulties come up. For instance, as Duclos et al. (2006) point out, any composite index requires a specific aggregation rule to sum up its components, and any such rule is necessarily arbitrary, leaving open the possibility that different rules could lead to contradictory conclusions about which groups have higher poverty. Furthermore, multidimensional poverty indices should take into account the possible dependence between poverty dimensions, since higher dependence could make overall poverty worse. However, most of the multidimensional poverty indices traditionally used are not sufficiently sensitive to this feature, making poverty comparisons somehow incomplete (Ferreira and Lugo, 2013).

To overcome these drawbacks, stochastic dominance techniques have been employed. These techniques allow to establish partial orders of distributions of random variables by providing criteria to perform global comparisons that complement those based on indicators. Since the seminal work of Lehmann (1955), this tool has been successfully employed in various fields, including economics and finance, where the early contributions of Hadar and Russell (1969), Hanoch and Levy (1969) and Rothschild and Stiglitz (1973) on decision theory under uncertainty stand out. After those pioneering works, stochastic dominance has been prominently applied in finance, as it offers the possibility of ordering distributions of random variables such as future returns to investments, thus being specially useful to solve problems related to portfolio selection and diversification; see the early work of Bawa (1978). Extensions of stochastic dominance to other fields of economics have also been conducted, including those in labour market (Gal et al., 1981) or firm theory under demand uncertainty (Leland, 1972). Early reviews, such as Bawa (1982) and Levy (1992), and more recently, Sriboonchitta et al. (2010), provide numerous references on the topic. In welfare economics, stochastic dominance methods have been considered a valuable tool to establish robust partial orders of distributions in terms 
of welfare and poverty. In this area, the papers of Shorrocks (1983), Atkinson (1987) and Foster and Shorrocks (1988) stand out.

The references mentioned above deal with unidimensional stochastic dominance, where only one random variable is considered. However, in the multivariate case, where the joint distribution of two or more random variables should be considered, the literature is scarce. Multivariate stochastic dominance conditions have been provided by Levy and Paroush (1974) in portfolio allocation; by Atkinson and Bourguignon (1982) in welfare economics; and by Atkinson (2003) and Duclos et al. (2006) in multivariate poverty. Noticeably, there have been few empirical applications of stochastic dominance concepts to cases with two or more dimensions, partly due to the difficulties to be mentioned below.

Despite its advantages, stochastic dominance techniques are not exempt of limitations. For instance, stochastic dominance does not allow to obtain cardinal results. That is, it tells you whether in one distribution there is more or less poverty than in another, but you cannot know how much poorer is one population with respect to the other. Moreover, in the multidimensional context, additional difficulties arise. First, the relationship between dominance conditions and poverty orderings depends on the type of relationship between the poverty dimensions. Second, as the number of dimensions grow, the conditions to establish multidimensional poverty orderings become more restrictive and harder to prove, making their implementation nearly unfeasible.

In this paper we attempt to bring together the literature on stochastic dominance and its applicability to both unidimensional and multidimensional poverty comparisons. The paper updates Zheng's (2000) review of dominance methods for unidimensional poverty analysis by discussing the most recent methodological contributions and applications in the literature. The paper also includes a novel review of the most recent literature on stochastic dominance and multidimensional poverty orderings. Although the paper focuses on stochastic dominance for poverty comparisons, the methods discussed can be easily extended to other fields of economics, 
such as finance and welfare, by just defining appropriately the corresponding families of utility functions.

The rest of the article is organised as follows. In Section 2 we focus on unidimensional stochastic dominance, reviewing its general definition and its application to poverty analysis. The multidimensional case is addressed in Section 3, providing a review of the conditions of multivariate stochastic dominance and their relationship with poverty orderings in the bidimensional case and also discussing the challenges that arise in the general $d$-dimensional setting when we have more than two dimensions. In both Sections 2 and 3, we will also go over some of the most relevant statistical tests that have been proposed for stochastic dominance in the literature, mentioning also some empirical applications of these tests. Finally, some concluding remarks are presented in Section 4.

\section{Univariate stochastic dominance}

In this section, we provide a review of the application of univariate stochastic dominance methods for obtaining robust poverty orderings. First, we focus on the concepts of first-order and higher-order stochastic dominance. After that, the relationship between the stochastic dominance conditions and poverty orderings is reviewed and the main issues concerning statistical inference and empirical applications are discussed.

\subsection{Concept of stochastic dominance}

Let $F$ and $G$ be two cumulative distribution functions (CDF) with support in the non-negative real line, for instance the income distributions of a country in two different periods or the income distributions of two different countries. We say that $G$ first-order stochastically dominates $F$, 
denoted as $G \succeq_{1} F$, if and only if

$$
G(x) \leq F(x) \forall x \in \Re_{+},
$$

with strict inequality for at least one $x$ (Hadar and Russell, 1969). ${ }^{1}$ That is, if $G$ is never above $F$; see the top panel in Figure 1.

$$
<\text { insert Figure } 1 \text { here }>
$$

Intuitively, if $x$ denotes an income level, then condition (1) means that the proportion of "poor" people (people with an income smaller than $x$ ) in distribution $F$ is at least as great as the proportion of "poor" people in distribution $G$ for any $x$.

It is also possible to define first-order stochastic dominance in terms of survival functions. In particular, let $\bar{F}$ be the survival function associated to $F$, defined as $\bar{F}(x)=1-F(x)$, and let $\bar{G}$ be defined in a similar way. Then, the following condition holds:

$$
G \succeq_{1} F \Leftrightarrow \bar{G}(x) \geq \bar{F}(x) \forall x \in \Re_{+} .
$$

Roughly speaking, if $x$ denotes an income level, then this condition means that the proportion of "rich" people (people with an income greater than $x$ ) in distribution $G$ is at least as great as the proportion of "rich" people in distribution $F$ for any $x$; see the central panel in Figure 1. First-order dominance can also be written in terms of quantiles. Actually, the quantile approach is more intuitive (it compares the relative position of every individual in both distributions), and could be more appropriate in many cases; see Levy (1992). Let $F^{-1}$ be the quantile function,

\footnotetext{
${ }^{1}$ For concreteness, we have assumed that $x$ can take any non-negative real value as this is the domain relevant for the measurement of poverty, which is the main focus of this paper. However, the domain can be extended to include any real number.
} 
defined as $F^{-1}(l)=\inf \{x: F(x) \geq l\}$ for a given $l \in[0,1]$. We say that

$$
G \succeq_{1} F \Leftrightarrow G^{-1}(l) \geq F^{-1}(l) \forall l \in[0,1],
$$

with strict inequality for at least one $l .^{2}$ This means that ranking the individuals of each population in terms of their income level, distribution $G$ first-order stochastically dominates distribution $F$ if the level of income in each position $l$ in $G$ is at least as high as the corresponding level of income in the same position in $F$; see the bottom panel in Figure 1.

When the cumulative distribution functions cross, it is not possible to establish a robust ordering between them and it is necessary to resort to second-order dominance. We say that $G$ secondorder stochastically dominates $F$, denoted as $G \succeq_{2} F$, if and only if

$$
\int_{t=0}^{x} G(t) d t \leq \int_{t=0}^{x} F(t) d t \forall x \in \Re_{+}
$$

see Hadar and Russell (1969). That is, distribution $G$ second-order stochastically dominates distribution $F$ when the area under $G$ is smaller than that under $F$. Second-order stochastic dominance can also be expressed in terms of quantiles. In particular,

$$
G \succeq_{2} F \Leftrightarrow \int_{t=0}^{l} G^{-1}(t) d t \geq \int_{t=0}^{l} F^{-1}(t) d t \quad \forall l \in[0,1]
$$

with strict inequality for at least one $l$. That is, distribution $G$ second-order stochastically dominates distribution $F$ when the area under $G^{-1}$ is smaller than that under $F^{-1}$. Furthermore, Atkinson (1970) and Shorrocks (1983) show that second-order stochastic dominance is equivalent to Generalised-Lorenz dominance.

The conditions of stochastic dominance of any order $\alpha$ can be defined by means of the general notation introduced by Davidson and Duclos (2000), which is based on the following functions:

\footnotetext{
${ }^{2}$ Actually, this definition is equivalent to the concept of rank dominance introduced by Saposnik (1981).
} 


$$
D^{1}(x)=F(x), \quad D^{\alpha}(x)=\int_{t=0}^{x} D^{\alpha-1}(t) d t, \quad \text { for } \alpha=2,3, \ldots
$$

As a general rule, $G$ stochastically dominates $F$ at order $\alpha$, denoted as $G \succeq_{\alpha} F$, if and only if

$$
D_{G}^{\alpha}(x) \leq D_{F}^{\alpha}(x) \forall x \in \Re_{+}
$$

with strict inequality for at least one $x$. Thus, when $\alpha=1$, the condition of stochastic dominance of first order in (1) comes up. In turn, when $\alpha=2$, the concept of second-order stochastic dominance in (4) comes up, and so on.

The definition above makes it clear that first-order dominance is the strongest condition and implies dominance of all higher orders. In particular, second-order dominance is implied by, but does not imply, first-order dominance; third-order dominance is implied by, but does not imply, first and second-order dominance; and so on. Then, lower-order dominance is a stronger condition than higher-order dominance.

\subsection{Univariate stochastic dominance and poverty}

In the literature of poverty measurement, one of the issues which has attracted more attention has been the appropriate way of aggregating information to obtain a single figure reflecting the overall level of poverty in a society. In this context, many different unidimensional poverty measures have been proposed; see Zheng (1997) and the references therein.

However, as Atkinson (1987) points out, when making poverty comparisons based on particular poverty measures some doubts about the robustness of the results may arise, as those indices are based on aggregation rules that require some methodological choices. To overcome this drawback, stochastic dominance techniques can be applied. In this section we explore the use of stochastic dominance techniques to obtain robust poverty orderings; see Zheng (2000) for an 
extensive review of this issue.

Let $X$ be a measure of income with CDF $F$ and let $z$ be the poverty line so that an individual is considered poor if her or his income is lower than $z$. Atkinson (1987) considers an aggregate poverty function $P_{F}(z)$, with $z>0$, defined as:

$$
P_{F}(z)=\int_{x=0}^{z} p(x ; z) d F(x)
$$

where $p(x ; z)$ is an individual poverty function such that $p(x ; z)=0$ for all $x \geq z{ }^{3}$ Here onwards we assume that $p(x ; z)$ is differentiable with respect to $x$ to the required degree. The general class of poverty measures given by $P_{F}(z)$ includes several well-known indices, such as those proposed by Watts (1968), Clark et al. (1981) and Foster et al. (1984). Furthermore, the individual poverty function $p(x ; z)$ in $(7)$ could be regarded as an individual disutility function analogue to the individual utility function $u(x, y)$ that is used to establish dominance conditions in economic problems involving making decisions under uncertainty; see, for instance, Hadar and Russell (1969), Hanoch and Levy (1969) and Whitmore (1970). Hence, the results to be discussed below could be easily extended to other fields of economics.

Once the poverty function is defined, we are able to compare the level of poverty of two distributions $F$ and $G$, given a common poverty line $z$, by evaluating the following difference:

$$
P_{G}(z)-P_{F}(z)=\int_{x=0}^{z} p(x ; z) d G(x)-\int_{x=0}^{z} p(x ; z) d F(x)
$$

Integrating by parts above, the following result comes up:

$$
P_{G}(z)-P_{F}(z)=-\int_{x=0}^{z} p_{x}(x ; z)[G(x)-F(x)] d x
$$

where $p_{x}(x ; z)$ denotes the first derivative of the individual poverty function with respect to

\footnotetext{
${ }^{3}$ We use the weak definition of the poor rather than the strong definition, which regards the persons at the poverty line as poor; see Donaldson and Weymark (1986) for a discussion on this issue.
} 
$x$. Then, as Atkinson (1987) and Foster and Shorrocks (1988) showed, the following condition holds:

$$
G \succeq_{1} F \Leftrightarrow P_{G}(z) \leq P_{F}(z) \forall p(x ; z) \mid p_{x}(x ; z) \leq 0 \forall z .
$$

That is, the level of poverty in $G$ is not higher than that in $F$ for all individual poverty measures that are decreasing in the level income $\left(p_{x}(x ; z) \leq 0\right)$ and for all poverty lines if and only if the proportion of people with an income smaller than $x$ ("poor" people) is at least as great in distribution $F$ as in distribution $G\left(G \succeq_{1} F\right)$. Therefore, first-order stochastic dominance constitutes the condition under which all poverty measures satisfying $p_{x}(x ; z) \leq 0$ rank distributions equally in terms of poverty. In particular, this condition is satisfied by wellknown poverty measures such as the indices proposed by Watts (1968), Thon (1979), Clark et al. (1981) and Chakravarty (1983); see Atkinson (1987) and Zheng (1999, 2000).

Despite its theoretical appeal, first-order stochastic dominance is a very demanding condition that many distributions may fail to satisfy, making it difficult to check in empirical applications and thus not leading to robust poverty orderings. To overcome this drawback, it is possible to resort to second-order dominance. With this approach, establishing poverty orderings requires an additional condition on the individual poverty function $p(x ; z)$ that fewer poverty measures will be able to fulfil. In particular, Atkinson (1987) shows that:

$$
G \succeq_{2} F \Leftrightarrow P_{G}(z) \leq P_{F}(z) \forall p(x ; z) \mid p_{x}(x ; z) \leq 0, p_{x x}(x ; z) \geq 0 \forall z
$$

where $p_{x x}(x ; z)$ denotes the second derivative of the individual poverty function with respect to $x$. Then, $G \succeq_{2} F$ if and only if the level of poverty in $G$ is not higher than that in $F$, for all poverty lines, according to all poverty measures that are decreasing in the level of income $\left(p_{x}(x ; z) \leq 0\right)$ and convex $\left(p_{x x}(x ; z) \geq 0\right)$. This latter property implies that poverty must increase after a regressive transfer between two poor individuals. Hence, as Atkinson (1987) and Zheng $(1999,2000)$ point out, the poverty ordering implied by second-order dominance will 
be respected by well-known poverty measures such as the indices proposed by Watts (1968) and Thon (1979) and the measure $P^{*}$ of Clark et al. (1981), among others.

When dominance analysis is not conclusive for first and second order, it is possible to resort to higher-order dominance conditions based on expression (6), but such conditions require more assumptions on $p(x ; z)$, reducing even more the number of poverty measures that will respect the poverty orderings obtained. However, the measures fulfilling such conditions are more sensitive to changes in the lower part of the income distribution, which some authors regard as a desirable property; see, for instance, Zheng (1997).

At this point, a special mention should be given to the relationship between stochastic dominance and the well-known family of FGT poverty measures proposed by Foster et al. (1984). These measures can be defined as follows (Foster and Shorrocks, 1988):

$$
F G T_{\alpha-1}(z)=\frac{1}{z^{\alpha-1}}(\alpha-1) ! D^{\alpha}(z)=\frac{1}{z^{\alpha-1}} \int_{x=0}^{z}(z-x)^{\alpha-1} d F(x) \quad \text { for } \alpha=1,2,3, \ldots
$$

where the function $D^{\alpha}(z)$ above is the function in equation (5) evaluated at the poverty line, which can be alternatively written as:

$$
D^{\alpha}(z)=\frac{1}{(\alpha-1) !} \int_{x=0}^{z}(z-x)^{\alpha-1} d F(x) \quad \text { for } \alpha=1,2,3, \ldots
$$

Taking $\alpha=1$ and $\alpha=2$ in equation (8), the headcount ratio $\left(F G T_{0}\right)$ and the poverty gap ratio $\left(F G T_{1}\right)$ in Foster et al. (1984) come up, respectively. The former gives the proportion of poor individuals in a population, whereas the latter measures the per capita differences between the poverty line and the income of the poor.

In this setting, the poverty orderings based on the FGT family turn out to be equivalent to those based on stochastic dominance conditions, since the following relationship holds:

$$
G \succeq_{\alpha} F \Leftrightarrow F G T_{G, \alpha-1}(z) \leq F G T_{F, \alpha-1}(z) \forall z
$$


This implies that $G \succeq_{1} F$ if and only if the headcount ratio in population $G$ is unambiguously lower than in $F$ for all poverty lines, that is, if the percentage of poor individuals in $G$ is lower than in $F$ for all poverty lines. Similarly, $G \succeq_{2} F$ if and only if the poverty gap ratio is lower in population $G$ than in population $F$ for all poverty lines.

To conclude this section, we would like to mention some issues regarding the role of the poverty line in poverty dominance analyses. As we have seen, stochastic dominance conditions are based on the comparison of two distributions over a common support. This means that, in order to obtain robust poverty orderings from stochastic dominance, it is necessary to compare two income distributions using a common poverty line $z$. Hence, when comparing two income distributions using two different poverty lines it is not possible to obtain robust poverty orderings based on the stochastic dominance conditions presented above. This weakness was pointed out by Davidson and Duclos (2000), who proposed an alternative strategy to obtain poverty

orderings when using different poverty lines for different income distributions. This strategy would allow researchers to obtain poverty orderings when using country-specific poverty lines, as it usually happens when analysing poverty in developed countries. On the other hand, not all values of the poverty line, $z$, are relevant in practice. Focusing on values of poverty lines in a certain range leads to the concept of restricted stochastic dominance; see Atkinson (1987) and Davidson and Duclos (2000).

\subsection{Statistical inference and empirical applications}

So far we have presented the theoretical results regarding the relationship between stochastic dominance conditions and robust poverty orderings. The question that immediately arises is: how can the dominance conditions presented above be applied in empirical studies? As it has been previously discussed, establishing poverty orderings amounts to comparing stochastic dominance for two distributions of income (or any other variable representing the level of welfare). However, in empirical applications, such distributions are not available for the whole 
population and it is necessary to work with sample data. Therefore, comparisons must be based on statistical functionals of the empirical distribution functions and statistical inference must be applied to determine whether the results of such comparisons are statistically significant; see Maasoumi (2001) for a comprehensive discussion on this topic. In this section, we briefly review some of the tests for univariate stochastic dominance proposed in the literature and some relevant empirical applications of them (see Table 1 for a summary).

Before going any further, it is important to note that the empirical application of the conditions of stochastic dominance requires overcoming a number of difficulties. The two main challenges are the following. First, to establish the null and alternative hypotheses of the test for stochastic dominance and second, to find an appropriate testing procedure, taking into account that dominance conditions involve the comparison of distributions over a large number of points. Regarding the former, the most common approach in the econometric literature (up to minor variations) has been testing the null of stochastic dominance against the alternative of lack of dominance, that is,

$$
H_{0}: G \succeq_{\alpha} F, \text { versus } H_{1}: G \nsucceq_{\alpha} F \text {. }
$$

This problem has been faced, among others, by McFadden (1989), Anderson (1996), Davidson and Duclos (2000), Barrett and Donald (2003), Linton et al. (2005) and Linton et al. (2010). As Davidson and Duclos (2013) note, to set this null hypothesis is "a matter of convention and convenience: convention in the sense that it follows the usual practice of making the theory of interest the null and seeking evidence contrary to it, and convenience in that the null is then relatively easy to formulate". However, as Álvarez-Esteban et al. (2017) point out, "the statistical meaning of not rejecting the null is simply to acknowledge that there is not evidence enough to guarantee that stochastic dominance does not hold", but this does not imply that distribution $G$ stochastically dominates distribution $F$, as it is sometimes invoked. Alternatively, if we are interested in gathering statistical evidence for stochastic dominance, we 
should test the null of non-dominance against the alternative of dominance, that is,

$$
H_{0}: G \nsucceq_{\alpha} F \text {, versus } H_{1}: G \succeq_{\alpha} F \text {. }
$$

This approach has the advantage that when the null is rejected, all that remains is dominance. Applications of this approach in welfare economics can be found, for instance, in Kaur et al. (1994) and Davidson and Duclos (2013). However, as Álvarez-Esteban et al. (2016, 2017) point out, the implementation of this approach is not exempt of caveats, as already noted by Davidson and Duclos (2013). Motivated by this fact, these authors propose relaxations of the stochastic dominance condition for which feasible statistical tests can be designed.

In any case, given that the null hypothesis involves in both cases composite hypotheses on inequality restrictions, ambiguous conclusions could arise about the relationship between $F$ and G. As Davidson and Duclos (2013) remark "the two approaches described above can thus be seen as complementary. Positing a null of dominance cannot be used to infer dominance; it can, however, serve to infer nondominance. Positing a null of nondominance cannot serve to infer nondominance; it can however lead to inferring dominance".

On the other hand, with respect to the testing procedure used to perform dominance tests two approaches can be distinguished, namely those which rely on comparing the underlying distributions at a finite grid of points and those based on Kolmogorov-Smirnov type statistics. Both types of tests have advantages and disadvantages. For instance, Tse and Zhang (2004) note that a selection of grid points can be argued to be arbitrary and Bennett (2008) argues that this method can lead to test inconsistency, as only a subset of the restrictions under the null are imposed. However, Bennett (2008) also indicates an advantage of these tests as compared to Kolmogorov-Smirnov type tests, since the former have distributions that are easier to characterise, whereas the latter have analytically intractable distributions and thus require simulation methods to obtain critical values. 
We begin reviewing those tests for stochastic dominance that refer to problem (9), distinguishing between those based on grid comparisons and those based on Kolmogorov-Smirnov type statistics. Regarding the former, the contribution of Bishop et al. (1992) can be highlighted. These authors propose testing the null of first-order stochastic dominance by means of a union-intersection strategy, previously developed by Bishop et al. (1989), which focuses on rank dominance, as defined in (3). In particular, given a grid of $K$ points, $0=l_{0}<l_{1}<\ldots<$ $l_{K-1}<l_{K}=1$, they propose to compare over this grid the conditional mean income of $F$ and $G$, namely $\mu_{i}^{F}$ and $\mu_{i}^{G}$, where $\mu_{i}^{F}=E\left[X \mid F^{-1}\left(l_{i-1}\right) \leq X \leq F^{-1}\left(l_{i}\right)\right]$ for $i=1, \ldots, K$ and $\mu_{i}^{G}$ is defined in a similar way. In order to do that, they use a t-type statistic for the hypotheses that the conditional means in each of the grid points are equal. The test statistic is defined as:

$$
T_{i}=\frac{\hat{\mu}_{i}^{G}-\hat{\mu}_{i}^{F}}{\left[\left(\frac{\hat{\sigma}_{i i}^{G}}{n^{G}}\right)+\left(\frac{\hat{\sigma}_{i i}^{F}}{n^{F}}\right)\right]^{1 / 2}} \text { for } i=1, \ldots, K
$$

where $\hat{\mu}_{i}^{G}$ and $\hat{\mu}_{i}^{F}$ are the sample conditional means, $\hat{\sigma}_{i i}^{G}$ and $\hat{\sigma}_{i i}^{F}$ are the corresponding estimated variances, and $n^{G}$ and $n^{F}$ are the sample sizes. The null hypothesis in (9) with $\alpha=1$ is rejected if any of the statistics $T_{i}$ is significant with a negative sign, where significance is determined asymptotically by the critical values of the Studentised Maximum Modulus (SMM) distribution with $K$ and an infinite number of degrees of freedom.

Analogously, Bishop et al. (1989) propose a test of second order stochastic dominance based on Generalised-Lorenz dominance, as both concepts are equivalent (see Section 2.1); see Xu (1997) for an alternative Generalised-Lorenz dominance testing procedure. Given two GeneralisedLorenz curves from two distribution functions $F$ and $G$, defined as $G L^{F}(l)=\int_{t=0}^{l} F^{-1}(t) d t$ and $G L^{G}(l)=\int_{t=0}^{l} G^{-1}(t) d t$, respectively, the estimated ordinates of these two curves are compared over the grid of $K$ points, based on the following test statistic:

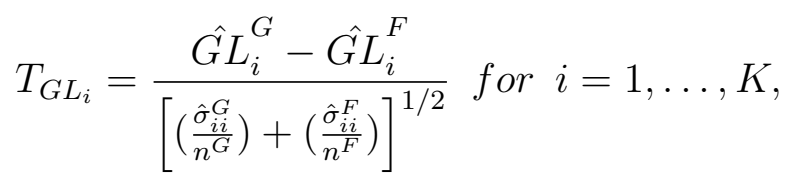


where $\hat{G L_{i}^{G}}$ and $\hat{G L_{i}^{F}}$ are the sample values of the ordinates of the Generalised Lorenz curve, $\hat{\sigma}_{i i}^{G}$ and $\hat{\sigma}_{i i}^{F}$ are the corresponding estimated variances, and $n^{G}$ and $n^{F}$ are the sample sizes. The strategy to perform this test is analogous to that described for first-order dominance. The null hypothesis in (9) with $\alpha=2$ is rejected if any of the statistics $T_{G L_{i}}$ is significant with a negative sign, where significance is determined asymptotically by the critical values of the Studentised Maximum Modulus (SMM) distribution with $K$ and an infinite number of degrees of freedom. Bishop et al. (1992) also illustrate their methodology by comparing South and non-South income distributions in the United States over the 70s. In particular, they test for first and secondorder stochastic dominance, finding evidence of convergence over the period analysed. Another application can be found in Madden and Smith (2000), who follow the approach of Bishop et al. (1992) to analyse the evolution of poverty in Ireland between 1987 and 1994, finding evidence that poverty decreased between these two years. Similarly, Ahamdanech et al. (2010) used the methodology of Bishop et al. (1989) and Bishop et al. (1992) to analyse Spanish regional convergence between 1990 and 2003, not finding a significant improvement in the convergence between regions.

The two testing procedures of Bishop et al. (1989) and Bishop et al. (1992) are valid for the case of independent samples. Another proposal for testing problem (9) based on the comparison over a grid of points is due to Davidson and Duclos (2000), who consider also the case of dependent samples. This proposal allows to test stochastic dominance of any order $\alpha$ for any two distributions $F$ and $G$. This test focuses on the concept of stochastic dominance defined in (6) and is based on the following test statistic:

$$
T_{D D_{i}}^{\alpha}=\frac{\hat{D}_{G_{i}}^{\alpha}-\hat{D}_{F_{i}}^{\alpha}}{\hat{\operatorname{Var}}\left(\hat{D}_{G_{i}}^{\alpha}-\hat{D}_{F_{i}}^{\alpha}\right)} \text { for } i=1, \ldots, K,
$$

where $\hat{D}_{G_{i}}^{\alpha}$ and $\hat{D}_{F_{i}}^{\alpha}$ are the estimators of the function in (5) for distributions $G$ and $F$, respectively, evaluated at the $i^{\text {th }}$ point in the grid. As Tse and Zhang (2004), Lean et al. (2008) and 
Sriboonchitta et al. (2010) argue, this test can be carried out by following the same strategy in Bishop et al. (1992) explained above. Davidson and Duclos (2000) also provide an empirical illustration of their test on poverty orderings for the United States, Canada, Norway and the Netherlands, using the Luxembourg Income Study (LIS) data set. In particular, they find dominance of Canada and the Netherlands over the United States both for first and second-order. An alternative stochastic dominance test for problem (9) based on comparisons over a grid of points can be found in Anderson (1996), who develops an analogue of the Pearson goodness of fit test based on the differences in the empirical distributions.

With respect to the literature on testing problem (9) through Kolmogorov-Smirnov type tests, the seminal paper of McFadden (1989) stands out. This proposal considers two independent populations and samples of equal size $(n)$ and is based on the following statistic:

$$
T_{M}^{\alpha}=\sqrt{n} \sup _{x}\left[\hat{D}_{G}^{\alpha}(x)-\hat{D}_{F}^{\alpha}(x)\right]
$$

where $\hat{D}_{G}^{\alpha}$ and $\hat{D}_{F}^{\alpha}$ are the same estimators explained before. The analysis of McFadden (1989) focuses on first and second-order dominance. For first-order dominance $(\alpha=1)$, the author shows that $T_{M}^{\alpha}$ is distribution free and provides both exact and asymptotic distributional results. In the case of second-order dominance $(\alpha=2)$, the limiting distribution of the test statistic depends on the underlying distribution and a simulation procedure is suggested for obtaining critical values. Klecan et al. (1991) extend McFadden's proposal to allow for dependent observations. Maasoumi and Heshmati (2000) apply those tests to analyse first and secondorder stochastic dominance between pre-government and post-government household income in Sweden, finding that Sweden's redistributive and welfare policies favour some groups. Also, Maasoumi and Heshmati (2005) provide an empirical application using the Michigan Panel Study of Income Dynamics.

Another extension of McFadden's test appears in Barrett and Donald (2003), who propose 
a consistent bootstrap test for stochastic dominance at any order in the case of independent samples from $F$ and $G$ and with possibly unequal sample sizes, $n^{G}$ and $n^{F}$, respectively. The test statistic proposed is

$$
T_{B D}^{\alpha}=\sqrt{\frac{n^{G} n^{F}}{n^{G}+n^{F}}} \sup _{x}\left[\hat{D}_{G}^{\alpha}(x)-\hat{D}_{F}^{\alpha}(x)\right] .
$$

On the other hand, Linton et al. (2005) consider a re-sampling method that applies to temporally and mutually dependent samples to compute the critical values of the test proposed by Klecan et al. (1991); see also the alternative proposal in Linton et al. (2010). More recently, Bennett (2013) proposes a modification of the union-intersection procedure in Bishop et al. (1989) and Bishop et al. (1992) using the test statistic in McFadden (1989), which has better properties in terms of both size and power.

The references discussed so far deal with testing for stochastic dominance by considering problem (9). Next, we review some contributions proposed in the econometric literature to face problem (10), i.e, to test the null of non-dominance against the alternative of dominance. For instance, Kaur et al. (1994) propose a consistent test for second-order dominance $(\alpha=2)$ using the following statistic:

$$
T_{K R S}^{\alpha}=\inf _{x}\left[\frac{\hat{D}_{G}^{\alpha}(x)-\hat{D}_{F}^{\alpha}(x)}{\hat{\operatorname{Var}}\left(\hat{D}_{G}^{\alpha}(x)-\hat{D}_{F}^{\alpha}(x)\right)}\right],
$$

and show that, for large sample sizes, the percentiles of the standard normal distribution serve as the critical values for this test. Tse and Zhang (2004) extend this test for $\alpha=1$ and $\alpha=3$. Another remarkable contribution in this area is Davidson and Duclos (2013), who propose a procedure based on an empirical likelihood ratio and apply it to perform comparisons of income distributions of the USA, the Netherlands, the UK, Germany and Ireland using the LIS data sets.

A comparative analysis of finite sample performance of some of the tests described above can be found in Tse and Zhang (2004). In particular, these authors compare finite sample sizes 
and powers of the tests proposed by Davidson and Duclos (2000), Anderson (1996) and Kaur et al. (1994), for independent and homoskedastic underlying distributions and they find that the latter is too conservative and has weaker power as compared to the other two. Furthermore, they conclude that the test of Davidson and Duclos (2000) appears to be the best in terms of both size and power. A similar study is undertaken by Lean et al. (2008) for correlated or heteroskedastic underlying distributions.

$<$ insert Table 1 here $>$

To finish this section a comment is needed on the software and codes available for performing stochastic dominance analysis. In this respect, the DASP Stata package developed by Araar and Duclos (2013) stands out. This package provides valuable tools that allow to perform poverty dominance analyses. Also, the rtip package in $\mathrm{R}$, due to Berihuete et al. (2018), allows to estimate the ordinates of the Generalised Lorenz curve and to test Generalised Lorenz dominance by means of the statistical testing procedure proposed by Xu (1997). Moberg and Solow (2015) also provide a code to test for stochastic dominance which is available both for MATLAB and R.

\section{Multivariate stochastic dominance}

In this section, we review the application of multivariate stochastic dominance methods to multidimensional poverty analysis. First, we focus on the concept of multivariate stochastic dominance and then we review the relationships between dominance conditions and bidimensional poverty orderings. A discussion on the additional difficulties that poverty dominance analysis with more than two variables entails, both from the theoretical and empirical point of view, is also included. The main issues concerning statistical inference and empirical applications are also treated. Finally, we will conclude this chapter reviewing some further issues 
regarding multidimensional poverty orderings.

\subsection{Concept of multivariate stochastic dominance}

Following the notation introduced by O'Brien and Scarsini (1991), let $\mathbf{X}=\left(X_{1}, X_{2}, \ldots, X_{d}\right)$ be a random $d$-dimensional vector and $\mathbf{x}=\left(x_{1}, x_{2}, \ldots, x_{d}\right)$ a real vector in $\Re_{+}^{d} \cdot{ }^{4}$ Also, let $L(\mathbf{x})=\left\{\mathbf{y} \in \Re_{+}^{d}\right.$ such that $\left.\mathbf{y} \leq \mathbf{x}\right\}$, where $\mathbf{y} \leq \mathbf{x}$ denotes $y_{i} \leq x_{i} \forall i$. Additionally, let $F$ be the d-dimensional joint cumulative distribution function of $\mathbf{X}$ and let $\succeq_{\alpha}^{M}$ denote multidimensional stochastic dominance of order $\alpha$.

The functions defined in (5) can be extended to the multidimensional case as:

$$
D^{1}(\mathbf{x})=F(\mathbf{x}), \quad D^{\alpha}(\mathbf{x})=\int_{L(\mathbf{x})} D^{\alpha-1}(\mathbf{t}) d \mathbf{t}, \text { for } \alpha=2,3, \ldots
$$

and the corresponding condition for multidimensional stochastic dominance at order $\alpha$ can be, by analogy to (6), written as:

$$
G \succeq_{\alpha}^{M} F \Leftrightarrow D_{G}^{\alpha}(\mathbf{x}) \leq D_{F}^{\alpha}(\mathbf{x}) \forall \mathbf{x} \in \Re_{+}^{d}
$$

To get a better insight into the meaning of (12), we further develop this concept for two dimensions $(d=2)$. In this case, from (11) and (12), the following condition of first-order dominance $(\alpha=1)$ comes up:

$$
G \succeq_{1}^{M} F \Leftrightarrow G\left(x_{1}, x_{2}\right) \leq F\left(x_{1}, x_{2}\right) \forall\left(x_{1}, x_{2}\right) \in \Re_{+}^{2}
$$

That is, there is first-order stochastic dominance of $G$ over $F$ if $G$ is never above $F$ and it is below for some values. Noticeably, if we denote by $F_{1}$ and $F_{2}\left(G_{1}\right.$ and $\left.G_{2}\right)$ the marginal distributions

\footnotetext{
${ }^{4} \mathrm{As}$ in the unidimensional case, we have assumed for concreteness that the variables of interest can take any non-negative real value as this is the domain relevant for the measurement of poverty, but it is possible to extended the domain to include any real number.
} 
of $F(G)$, then $G \succeq_{1}^{M} F$ implies univariate dominance in both marginal distributions, that is $G_{1} \succeq_{1} F_{1}$ and $G_{2} \succeq_{1} F_{2}$, since:

$$
\begin{aligned}
& G_{1}\left(x_{1}\right)=\lim _{x_{2} \rightarrow+\infty} G\left(x_{1}, x_{2}\right) \leq \lim _{x_{2} \rightarrow+\infty} F\left(x_{1}, x_{2}\right)=F_{1}\left(x_{1}\right) \forall x_{1}, \\
& G_{2}\left(x_{2}\right)=\lim _{x_{1} \rightarrow+\infty} G\left(x_{1}, x_{2}\right) \leq \lim _{x_{1} \rightarrow+\infty} F\left(x_{1}, x_{2}\right)=F_{2}\left(x_{2}\right) \forall x_{2} .
\end{aligned}
$$

As in the unidimensional case, when no conclusions can be reached analysing first-order dominance, it is necessary to resort to second-order stochastic dominance. In this case, taking $\alpha=2$ in (11) and (12), the following condition holds:

$$
G \succeq_{2}^{M} F \Leftrightarrow \int_{s_{1}=0}^{x_{1}} \int_{s_{2}=0}^{x_{2}} G\left(s_{1}, s_{2}\right) d s_{1} d s_{2} \leq \int_{s_{1}=0}^{x_{1}} \int_{s_{2}=0}^{x_{2}} F\left(s_{1}, s_{2}\right) d s_{1} d s_{2} \quad \forall\left(x_{1}, x_{2}\right) \in \Re_{+}^{2} .
$$

That is, $G$ second-order stochastically dominates $F$ if and only if the volume under $G$ is not greater than that under $F$. Conditions for higher dimensions $(d>2)$ and higher orders $(\alpha>2)$ can be worked out in a similar fashion.

Over the rest of this section we focus on the application of these concepts to establish multidimensional poverty orderings. To start with, in the next subsection we focus on the bidimensional case. Then, in Section 3.3, a discussion of the general $d$-dimensional case $(d>2)$ and its potential limitations for conducting dominance analyses will also be provided.

\subsection{Bivariate stochastic dominance and bidimensional poverty}

As we said in the Introduction, there is a general agreement that poverty is a multidimensional phenomenon, involving not only income, but also other non-monetary dimensions such as health, education, labour, etc. However, there is not a consensus on how to perform poverty comparisons in this multivariate setting; see Ferreira and Lugo (2013). The approach most widely used has been based on comparing multidimensional poverty measures that aggregate 
somehow the information across dimensions and individuals; see the reviews of Alkire et al. (2015) and Aaberge and Brandolini (2015) and the references therein. However, as in the unidimensional case, this approach could suffer from lack of robustness, since the choice of different measures of multidimensional poverty may lead to different orderings. Moreover, as Ferreira and Lugo (2013) and Duclos and Tiberti (2016) point out, the most commonly used multidimensional poverty indices do not take properly into account the degree of dependence between dimensions, making comparisons somehow incomplete.

To overcome these problems and obtain robust multidimensional poverty orderings, multivariate stochastic dominance techniques have been proposed. The advantage of these methods is that they capture the possible relationships between the dimensions of poverty, as they rely upon their joint distribution. This subsection is devoted to the application of these techniques to establish poverty orderings in the bidimensional case, as this is the case considered by the vast majority of applications that can be found in the literature. Special attention will be paid to the role that the type of relationship between dimensions plays in establishing such orderings. To begin with, it is important to highlight that bidimensional poverty analyses focus on the lowest part of the joint distributions and hence the domain of interest is that including the values of $X_{1}$ and $X_{2}$ up to the poverty lines for these variables. Let $\mathbf{z}=\left(z_{1}, z_{2}\right)$ be the vector of these poverty lines and let $P_{F}$ be an additive multidimensional poverty measure given by:

$$
P_{F}(\mathbf{z})=\int_{x_{1}=0}^{z_{1}} \int_{x_{2}=0}^{z_{2}} p\left(x_{1}, x_{2} ; \mathbf{z}\right) d F\left(x_{1}, x_{2}\right)
$$

where $p\left(x_{1}, x_{2} ; \mathbf{z}\right)$ is an individual poverty function that is differentiable up to the required degree and takes the value 0 if the individual is not poor and a positive value when the individual is considered poor. Notice that the individual poverty function $p\left(x_{1}, x_{2} ; \mathbf{z}\right)$ can be considered as a disutility function analogue to the individual utility function $u\left(x_{1}, x_{2}\right)$ that is used to establish dominance conditions in other economic fields; see, for instance, Levy and Paroush 
(1974), Atkinson and Bourguignon (1982), Mosler and Scarsini (1991) or Denuit and Eeckhoudt (2010), among others. Hence, the results to be discussed below could be easily extended to other fields of economics.

Once the poverty measure in (14) is defined, poverty orderings between $F$ and $G$ are established by computing the difference in the level of poverty of the two distributions as follows:

$$
P_{G}(\mathbf{z})-P_{F}(\mathbf{z})=\int_{x_{1}=0}^{z_{1}} \int_{x_{2}=0}^{z_{2}} p\left(x_{1}, x_{2} ; \mathbf{z}\right) d G\left(x_{1}, x_{2}\right)-\int_{x_{1}=0}^{z_{1}} \int_{x_{2}=0}^{z_{2}} p\left(x_{1}, x_{2} ; \mathbf{z}\right) d F\left(x_{1}, x_{2}\right) .
$$

Integrating by parts above, the following equation is obtained:

$$
\begin{aligned}
& P_{G}(\mathbf{z})-P_{F}(\mathbf{z})=-\int_{x_{1}=0}^{z_{1}} p_{1}\left(x_{1}, z_{2} ; \mathbf{z}\right)\left[G_{1}\left(x_{1}\right)-F_{1}\left(x_{1}\right)\right] d x_{1}-\int_{x_{2}=0}^{z_{2}} p_{2}\left(z_{1}, x_{2} ; \mathbf{z}\right)\left[G_{2}\left(x_{2}\right)-F_{2}\left(x_{2}\right)\right] d x_{2} \\
& \quad+\int_{x_{1}=0}^{z_{1}} \int_{x_{2}=0}^{z_{2}} p_{12}\left(x_{1}, x_{2} ; \mathbf{z}\right)\left[G\left(x_{1}, x_{2}\right)-F\left(x_{1}, x_{2}\right)\right] d x_{2} d x_{1}
\end{aligned}
$$

where $p_{1}$ and $p_{2}$ denote the partial derivative of the individual poverty function with respect to $x_{1}$ and with respect to $x_{2}$, respectively, and $p_{12}$ denotes the cross-partial derivative of the individual poverty function.

Alternatively, it is possible to rewrite (15) in terms of survival functions as follows:

$$
\begin{aligned}
& P_{G}(\mathbf{z})-P_{F}(\mathbf{z})=\int_{x_{1}=0}^{z_{1}} p_{1}\left(x_{1}, 0 ; \mathbf{z}\right)\left[\bar{G}_{1}\left(x_{1}\right)-\bar{F}_{1}\left(x_{1}\right)\right] d x_{1}+\int_{x_{2}=0}^{z_{2}} p_{2}\left(0, x_{2} ; \mathbf{z}\right)\left[\bar{G}_{2}\left(x_{2}\right)-\bar{F}_{2}\left(x_{2}\right)\right] d x_{2} \\
+ & \int_{x_{1}=0}^{z_{1}} \int_{x_{2}=0}^{z_{2}} p_{12}\left(x_{1}, x_{2} ; \mathbf{z}\right)\left[\bar{G}\left(x_{1}, x_{2}\right)-\bar{F}\left(x_{1}, x_{2}\right)\right] d x_{2} d x_{1}
\end{aligned}
$$

where $\bar{F}$ is defined as $\bar{F}\left(x_{1}, x_{2}\right)=\operatorname{Pr}\left(X_{1}>x_{1}, X_{2}>x_{2}\right)$ and $\bar{G}$ is defined similarly.

Notice that the difference $P_{G}(\mathbf{z})-P_{F}(\mathbf{z})$ in expressions (15) and (16) depends on three terms. The first two terms involve the univariate marginal distributions and thus they are based on the marginal behaviour of the variables, as in a unidimensional approach to poverty measurement. But there is also a third term, based on the joint distribution of the variables, which is the 
cornerstone when it comes to measuring poverty from a bidimensional perspective. Actually, the sign of cross-partial derivative $p_{12}\left(x_{1}, x_{2} ; \mathbf{z}\right)$ determines the effect of the type of relationship between the dimensions on the level of poverty; see Bourguignon and Chakravarty (2003). In fact, this has to do with the concepts of substitutability and complementarity in the AuspitzLieben-Edgeworth-Pareto (ALEP) sense to be explained below.

The ALEP relationships were originally defined in terms of the properties of a utility function $u\left(x_{1}, x_{2}\right)$ which is differentiable to the required degree; see Kannai (1980). In particular, it is said that two dimensions are ALEP substitutes if $u_{12} \leq 0$, where $u_{12}$ is the cross-derivative of $u\left(x_{1}, x_{2}\right)$. Intuitively, with this property the increase in utility that follows an increment in one dimension, decreases with the value of the other. In our setting, this condition leads to the following condition $p_{12}\left(x_{1}, x_{2} ; \mathbf{z}\right) \geq 0$; see Atkinson (2003). That is, the magnitude of the decrease in poverty that follows an increment in one dimension decreases with the level of the other dimension.

On the other hand, two dimensions $x_{1}$ and $x_{2}$ are ALEP complements if $u_{12} \geq 0$. Intuitively, with ALEP complementarity the increase in utility that follows an increment in one dimension increases with the value of the other. Notice that, in our setting, a poverty function satisfying ALEP complementarity requires $p_{12}\left(x_{1}, x_{2} ; \mathbf{z}\right) \leq 0$; see Atkinson (2003). That is, the magnitude of the decrease in poverty that follows an increment in one dimension increases with the level of the other dimension.

Finally, it is also possible to consider that the dimensions are ALEP neutral. In this case, we have $u_{12}=0$, which means that the increase in utility that follows an increment in one dimension does not depend on the level of the other dimension. In our setting, a poverty function satisfying neutrality requires $p_{12}\left(x_{1}, x_{2} ; \mathbf{z}\right)=0$. This would mean that the decrease in poverty that is consequence of an increment in one dimension does not depend on the level of the other dimension. Noticeably, in this case, the difference $P_{G}(\mathbf{z})-P_{F}(\mathbf{z})$ in expressions (15) and (16) would only depend on the behaviour of the marginal distributions. 
Over the next subsections we will review the relationship between stochastic dominance conditions and poverty orderings in the bidimensional case focusing on first-order dominance and second-order dominance, the cases most frequently used in the literature.

\subsubsection{First-order dominance}

The relationship between first-order stochastic dominance conditions and bidimensional poverty orderings can be established from either equation (15) or equation (16). As we will see, depending on which one we use, different conclusions will come out, which are related to whether the dimensions are considered as complementary, substitutives or neutral.

First, considering both equations (13) and (15), the following condition for $\alpha=1$ holds:

$G \succeq_{1}^{M} F \Leftrightarrow P_{G}(\mathbf{z}) \leq P_{F}(\mathbf{z}) \forall p \mid p_{1}\left(x_{1}, x_{2} ; \mathbf{z}\right) \leq 0, \quad p_{2}\left(x_{1}, x_{2} ; \mathbf{z}\right) \leq 0, \quad p_{12}\left(x_{1}, x_{2} ; \mathbf{z}\right) \geq 0 \forall \mathbf{z} \in \Re_{+}^{2}$.

This condition states that if $G \succeq_{1}^{M} F$, then the level of poverty in $G$ is not higher than that in $F$ for all bidimensional poverty measures that are decreasing in both $\operatorname{arguments}\left(p_{1}\left(x_{1}, x_{2} ; \mathbf{z}\right) \leq\right.$ $\left.0, p_{2}\left(x_{1}, x_{2} ; \mathbf{z}\right) \leq 0\right)$ and assume ALEP substitutability between dimensions $\left(p_{12}\left(x_{1}, x_{2} ; \mathbf{z}\right) \geq 0\right)$ for all vectors of poverty lines $\mathbf{z}^{5}$

Noticeably, taking into account that $F\left(x_{1}, x_{2}\right)=\operatorname{Pr}_{F}\left(X_{1} \leq x_{1}, X_{2} \leq x_{2}\right)$, condition (17) has an interpretation in terms of the probability of the intersection and it is thus linked to the intersection approach in multidimensional poverty measurement. Recall that in the bivariate case, this approach considers an individual as poor if he is simultaneously deprived in both dimensions; the left-hand panel of Figure 2 illustrates this concept, being the poor individuals those who lie within the grey area of this figure. Therefore, $G \succeq_{1}^{M} F$ states that, regardless of the poverty lines, the probability of being poor according to the intersection approach is lower in

\footnotetext{
${ }^{5}$ In practice, and similarly to the unidimensional case, when analysing multidimensional poverty, not all values of the poverty line vector $\mathbf{z}$, are relevant and restricted stochastic dominance analysis can be applied, determining whether there is dominance of one distribution over another for a certain range of poverty lines.
} 
distribution $G$ than in distribution $F$. Hence, condition (17) states that when this happens, then bidimensional poverty in $G$ is lower than in $F$ according to all additive bidimensional poverty measures that are decreasing and whose arguments are ALEP substitutes. For example, if $X_{1}$ is income and $X_{2}$ is the level of education, when the probability of being simultaneously poor in income and education is lower in $G$ than in $F$, then multidimensional poverty in $G$ is lower than in $F$. This poverty ordering will be respected by all additive multidimensional poverty measures that are decreasing and whose arguments are ALEP substitutes.

$<$ Insert Figure 2 here $>$

In a similar way, a poverty ordering based on the survival functions can be established from equation (16), namely:

$$
\begin{aligned}
\bar{G}\left(x_{1}, x_{2}\right) \geq \bar{F}\left(x_{1}, x_{2}\right) \forall\left(x_{1}, x_{2}\right) \in \Re_{+}^{2} \Leftrightarrow \\
\Leftrightarrow \quad P_{G}(\mathbf{z}) \leq P_{F}(\mathbf{z}) \forall p \mid p_{1}\left(x_{1}, x_{2} ; \mathbf{z}\right) \leq 0, \quad p_{2}\left(x_{1}, x_{2} ; \mathbf{z}\right) \leq 0, \quad p_{12}\left(x_{1}, x_{2} ; \mathbf{z}\right) \leq 0 \quad \forall \mathbf{z} \in \Re_{+}^{2}
\end{aligned}
$$

Condition (18) states that, if the joint survival function $\bar{G}$ lies entirely, or partly, above $\bar{F}$ for all $\left(x_{1}, x_{2}\right)$, then $P_{G} \leq P_{F}$ for all poverty lines according to all additive multidimensional poverty measures that are decreasing in both arguments $\left(p_{1}\left(x_{1}, x_{2} ; \mathbf{z}\right) \leq 0, p_{2}\left(x_{1}, x_{2} ; \mathbf{z}\right) \leq 0\right)$ and assume ALEP complementarity between dimensions $\left(p_{12}\left(x_{1}, x_{2} ; \mathbf{z}\right) \leq 0\right)$.

Now, since the survival function can be expressed in terms of the probability of the union as $\bar{F}\left(x_{1}, x_{2}\right)=1-\operatorname{Pr}_{F}\left(\left(X_{1} \leq x_{1}\right) \cup\left(X_{2} \leq x_{2}\right)\right)$, condition (18) is related to the union approach in multidimensional poverty measurement. According to this approach, an individual is considered as poor in a bidimensional setting if he is deprived in at least one of the two dimensions, that is if the individual lies within the grey area of the right-hand panel in Figure 2. In particular, since

$$
\bar{G}\left(x_{1}, x_{2}\right) \geq \bar{F}\left(x_{1}, x_{2}\right) \Leftrightarrow \operatorname{Pr}_{G}\left(\left(X_{1} \leq x_{1}\right) \cup\left(X_{2} \leq x_{2}\right) \leq \operatorname{Pr}_{F}\left(\left(X_{1} \leq x_{1}\right)\right) \cup\left(X_{2} \leq x_{2}\right)\right)
$$


condition (18) states that, regardless of the poverty line, if the probability of being poor according to the union approach is lower in $G$ than in $F$, then $P_{G} \leq P_{F}$ according to all additive bidimensional poverty measures that are decreasing in both arguments and assume ALEP complementarity between dimensions, for all vectors of poverty lines z. For instance, if variable $X_{1}$ is the level of education and $X_{2}$ is the nutritional status, when the probability of being poor in education or being poor in nutrition is lower in $G$ than in $F$, multidimensional poverty in $G$ is lower than in $F$.

Additionally, Atkinson and Bourguignon (1982) show that:

$$
\begin{array}{r}
G\left(x_{1}, x_{2}\right) \leq F\left(x_{1}, x_{2}\right) \forall\left(x_{1}, x_{2}\right) \in \Re_{+}^{2} \text { and } \bar{G}\left(x_{1}, x_{2}\right) \geq \bar{F}\left(x_{1}, x_{2}\right) \forall\left(x_{1}, x_{2}\right) \in \Re_{+}^{2} \Leftrightarrow \\
\Leftrightarrow P_{G}(\mathbf{z}) \leq P_{F}(\mathbf{z}) \forall p \mid p_{1}\left(x_{1}, x_{2} ; \mathbf{z}\right) \leq 0, p_{2}\left(x_{1}, x_{2} ; \mathbf{z}\right) \leq 0, \quad \forall \mathbf{z} \in \Re_{+}^{2}
\end{array}
$$

That is, according to condition (19), poverty in $G$ is not higher than that in $F$ for all bidimensional poverty measures that are decreasing in both arguments, for all vectors of poverty lines $\mathbf{z}$, if and only if there exists bivariate stochastic dominance of $G$ over $F$ both in the joint CDF and in the joint survival function.

Finally, from equation (15) we also have the following result:

$$
\begin{aligned}
& G_{1}\left(x_{1}\right) \leq F_{1}\left(x_{1}\right) \forall x_{1} \in \Re_{+} \text {and } G_{2}\left(x_{2}\right) \leq F_{2}\left(x_{2}\right) \forall x_{2} \in \Re_{+} \Leftrightarrow \\
& \quad \Leftrightarrow \quad P_{G}(\mathbf{z}) \leq P_{F}(\mathbf{z}) \forall p \mid p_{1}\left(x_{1}, x_{2} ; \mathbf{z}\right) \leq 0, \quad p_{2}\left(x_{1}, x_{2} ; \mathbf{z}\right) \leq 0, \quad p_{12}\left(x_{1}, x_{2} ; \mathbf{z}\right)=0 \forall \mathbf{z} \in \Re_{+}^{2}
\end{aligned}
$$

This means that, if both marginal distribution functions of $G$ lie below those of $F$, then poverty is lower in distribution $G$ than in distribution $F$ for all additive multidimensional poverty measures that are decreasing in both arguments $\left(p_{1}\left(x_{1}, x_{2} ; \mathbf{z}\right) \leq 0, p_{2}\left(x_{1}, x_{2} ; \mathbf{z}\right) \leq 0\right)$ and assume ALEP neutrality between dimensions $\left(p_{12}\left(x_{1}, x_{2} ; \mathbf{z}\right)=0\right)$. Hence, in this case the poverty ordering only depends on the marginal distributions. In other words, when the probability of being 
poor in dimension $X_{1}$ and the probability of being poor in dimension $X_{2}$ are both lower in $G$ than in $F$ for all possible poverty lines, then poverty in distribution $G$ is lower than poverty in distribution F. Moreover, this ordering is respected by all additive multidimensional poverty measures that are decreasing in their arguments and assume ALEP neutrality.

At this point, an important difference between unidimensional and bidimensional stochastic dominance must be introduced. In the unidimensional case, there was an equivalence between first-order dominance definition in terms of cumulative distribution functions and in terms of survival functions; see equations (1) and (2), respectively. However, this equivalence is no longer true in the bidimensional case. In fact, taking into account that:

$$
F\left(x_{1}, x_{2}\right)=\bar{F}\left(x_{1}, x_{2}\right)+F_{1}\left(x_{1}\right)+F_{2}\left(x_{2}\right)-1,
$$

and that the same condition holds for $G$, it turns out that:

$$
G\left(x_{1}, x_{2}\right) \leq F\left(x_{1}, x_{2}\right) \Leftrightarrow \bar{G}\left(x_{1}, x_{2}\right)+G_{1}\left(x_{1}\right)+G_{2}\left(x_{2}\right) \leq \bar{F}\left(x_{1}, x_{2}\right)+F_{1}\left(x_{1}\right)+F_{2}\left(x_{2}\right) .
$$

Therefore, if we deal with two bivariate distributions $F$ and $G$, the conditions $G\left(x_{1}, x_{2}\right) \leq$ $F\left(x_{1}, x_{2}\right)$ and $\bar{G}\left(x_{1}, x_{2}\right) \geq \bar{F}\left(x_{1}, x_{2}\right)$ can hardly hold simultaneously, as they do hold in the univariate case. In particular, if we have two distinct joint distributions $\left(G\left(x_{1}, x_{2}\right) \neq F\left(x_{1}, x_{2}\right)\right.$ for some $\left.\left(x_{1}, x_{2}\right)\right)$ with identical marginals $\left(F_{1}=G_{1}\right.$ and $\left.F_{2}=G_{2}\right)$, conditions (17) and (18) cannot be satisfied simultaneously, and therefore condition (19) cannot hold.

As it happened in the unidimensional case, first-order dominance results in the bidimensional case impose strong requirements on the distributions, making them difficult to check in empirical applications and thus not leading, in some cases, to robust poverty orderings; see Atkinson and Bourguignon (1982). Hence, it is necessary to resort to second-order dominance, imposing further conditions on the function $p\left(x_{1}, x_{2} ; \mathbf{z}\right)$, as we will see in the next subsection. 


\subsubsection{Second-order dominance}

Atkinson and Bourguignon (1982) proved the relationship between second-order dominance conditions and bidimensional welfare orderings. Based on this result, it is possible to work out the relationship between second-order conditions and bidimensional poverty orderings. This requires the assumption of further conditions about the poverty measure, which will limit the number of poverty measures that will respect the orderings.

At this point, some further notation should be introduced. Let $p_{i j}\left(x_{1}, x_{2} ; \mathbf{z}\right)=\frac{\partial^{2} p\left(x_{1}, x_{2} ; \mathbf{z}\right)}{\partial x_{i} \partial x_{j}}$ with $i=1,2$ and $j=1,2$ and $p_{i j k}\left(x_{1}, x_{2} ; \mathbf{z}\right)=\frac{\partial^{3} p\left(x_{1}, x_{2} ; \mathbf{z}\right)}{\partial x_{i} \partial x_{j} \partial x_{k}}$ with $i=1,2 ; j=1,2$ and $k=$ 1,2, and so on. Then, for poverty functions satisfying: $p_{1}\left(x_{1}, x_{2} ; \mathbf{z}\right) \leq 0, p_{2}\left(x_{1}, x_{2} ; \mathbf{z}\right) \leq 0$, $p_{12}\left(x_{1}, x_{2} ; \mathbf{z}\right) \geq 0, \quad p_{11}\left(x_{1}, x_{2} ; \mathbf{z}\right) \geq 0, \quad p_{22}\left(x_{1}, x_{2} ; \mathbf{z}\right) \geq 0, \quad p_{112}\left(x_{1}, x_{2} ; \mathbf{z}\right) \leq 0, \quad p_{122}\left(x_{1}, x_{2} ; \mathbf{z}\right) \leq 0$, and $p_{1122}\left(x_{1}, x_{2} ; \mathbf{z}\right) \geq 0$, the condition $P_{G}(\mathbf{z}) \leq P_{F}(\mathbf{z})$ holds if and only if:

$$
\begin{aligned}
\int_{x_{1}=0}^{z_{1}} G_{1}\left(x_{1}\right) d x_{1} & \leq \int_{x_{1}=0}^{z_{1}} F_{1}\left(x_{1}\right) d x_{1} \forall z_{1} \in \Re_{+}, \\
\int_{x_{2}=0}^{z_{2}} G_{2}\left(x_{2}\right) d x_{2} & \leq \int_{x_{2}=0}^{z_{2}} F_{2}\left(x_{2}\right) d x_{2} \forall z_{2} \in \Re_{+}, \\
\int_{x_{1}=0}^{z_{1}} \int_{x_{2}=0}^{z_{2}} G\left(x_{1}, x_{2}\right) d x_{2} d x_{1} & \leq \int_{x_{1}=0}^{z_{1}} \int_{x_{2}=0}^{z_{2}} F\left(x_{1}, x_{2}\right) d x_{2} d x_{1} \quad \forall \mathbf{z} \in \Re_{+}^{2} .
\end{aligned}
$$

Therefore, $P_{G}(\mathbf{z}) \leq P_{F}(\mathbf{z})$ if and only if distribution $G$ second-order stochastically dominates distribution $F$ both in the joint $\mathrm{CDF}$ and in the marginal distributions.

On the other hand, for poverty functions satisfying $p_{1}\left(x_{1}, x_{2} ; \mathbf{z}\right) \leq 0, p_{2}\left(x_{1}, x_{2} ; \mathbf{z}\right) \leq 0, p_{12}\left(x_{1}, x_{2} ; \mathbf{z}\right) \leq$ $0, p_{11}\left(x_{1}, x_{2} ; \mathbf{z}\right) \geq 0, p_{22}\left(x_{1}, x_{2} ; \mathbf{z}\right) \geq 0, p_{112}\left(x_{1}, x_{2} ; \mathbf{z}\right) \geq 0, p_{122}\left(x_{1}, x_{2} ; \mathbf{z}\right) \geq 0$ and $p_{1122}\left(x_{1}, x_{2} ; \mathbf{z}\right) \leq$ 0, the condition $P_{G}(\mathbf{z}) \leq P_{F}(\mathbf{z})$ holds if and only if conditions (20a) and (20b) are satisfied and also the following condition on the joint survival function holds:

$$
\int_{x_{1}=0}^{z_{1}} \int_{x_{2}=0}^{z_{2}} \bar{G}\left(x_{1}, x_{2}\right) d x_{2} d x_{1} \geq \int_{x_{1}=0}^{z_{1}} \int_{x_{2}=0}^{z_{2}} \bar{F}\left(x_{1}, x_{2}\right) d x_{2} d x_{1} \quad \forall \mathbf{z} \in \Re_{+}^{2} .
$$


Therefore, in this case, $P_{G}(\mathbf{z}) \leq P_{F}(\mathbf{z})$ if and only if distribution $G$ second-order stochastically dominates distribution $F$ in the marginals and in the joint survival functions.

It could also be possible to establish the relationship between higher-order dominance $(\alpha>$ 2) and poverty orderings by imposing more demanding conditions on the individual poverty function. However, to check that these conditions are fulfilled becomes a difficult task and so the empirical applications for higher-order dominance are scarce; see the contribution of Crawford (2005) to be discussed in Section 3.4.

\subsection{A discussion on higher dimensions}

So far, we have reviewed the relationship between bivariate stochastic dominance conditions and bidimensional poverty orderings. Although it is possible to extend these results to more than two dimensions, the literature on this issue is very scarce due to the problems that stochastic dominance involves in a $d$-dimensional setting with $d>2$. First, stochastic dominance methods suffer from the curse of dimensionality, that is, as the number of dimensions increases so does the difficulty to compare distributions as well as the possibility to obtain conclusive results. Furthermore, the relationship between stochastic dominance and poverty orderings in the $d$ dimensional case with $d>2$ relies on the sign of higher-order partial derivatives of the individual poverty function, and these signs are difficult to interpret, making the analysis cumbersome. In spite of these difficulties, the relationship between first-order stochastic dominance and welfare orderings for the general case of $d$ dimensions is treated by Crawford (2005).

Based on his results, it is possible to work out the relationship between first-order multivariate stochastic dominance conditions and multidimensional poverty orderings. In particular, suppose that poverty depends on $d$ variables $X_{1}, \ldots, X_{d}$ whose poverty lines are those included on the vector $\mathbf{z}=\left(z_{1}, \ldots, z_{d}\right)$. Then, the $d$-dimensional analogue to the bidimensional poverty function 
defined in (14) is:

$$
P_{F}(\mathbf{z})=\int_{x_{1}=0}^{z_{1}} \ldots \int_{x_{d}=0}^{z_{d}} p\left(x_{1}, \ldots, x_{d} ; \mathbf{z}\right) d F\left(x_{1}, \ldots, x_{d}\right)
$$

where $p\left(x_{1}, \ldots, x_{d} ; \mathbf{z}\right)$ is an individual poverty function that is differentiable up to the required degree and takes the value 0 if the individual is not poor and a positive value when the individual is considered poor.

In order to establish poverty orderings between two distributions $F$ and $G$, the difference $P_{F}(\mathbf{z})-P_{G}(\mathbf{z})$ will be calculated, as in the lower dimensions cases. Integrating by parts this difference, as we did in both the unidimensional and bidimensional cases, to obtain conditions for first-order dominance, we would end up with a cumbersome expression in which there are $2^{d}-1$ partial derivatives, namely $d$ partial derivatives of the individual poverty function with respect to individual variables, which are assumed negative, and $2^{d}-d-1$ cross-partial derivatives whose signs will be assigned, depending on the type of relationship among the variables; see Crawford (2005). For example, in the bidimensional case, which has been extensively treated above, the relationship between bivariate stochastic dominance and bidimensional poverty orderings depends on the sign of two partial derivatives with respect to individual variables and one cross-partial derivative. In the tridimensional case $(d=3)$, there are three first-order partial derivatives and four cross-partial derivatives, whose signs will determine the relationship between dominance conditions and multidimensional poverty orderings. Obviously, the number of partial derivatives that are involved in the analysis increases rapidly with the number of dimensions and the sign of the higher-order derivatives, which determine the relationship between stochastic dominance and poverty orderings, become difficult to interpret. This, together with the increasing difficulty of obtaining conclusive results, are the reasons why most applications of multivariate stochastic dominance techniques to poverty analyses confine to the bidimensional case and only few papers tackle tridimensional problems, as we will see in the next subsection. Moreover, to the best of our knowledge, there is not any paper focusing on the 
relationship between second-order stochastic dominance and poverty orderings for the general $d$-dimensional case and there are no applications dealing with second-order dominance with more than two dimensions.

\subsection{Statistical inference and empirical applications}

As we have just said, in the multivariate framework, the literature on statistical inference for stochastic dominance analyses is scarce and it is mainly devoted to the bidimensional case. The few proposals available are based on extending some of the tests discussed in section 2.3 for the univariate case. For instance, Duclos et al. (2006) extend the test of Davidson and Duclos (2000) to obtain robust poverty orderings in the bidimensional and tridimensional cases. In particular, bidimensional poverty orderings between rural and urban children in Vietnam are analysed, using data on per capita household expenditures and nutritional status and it is shown that rural children are poorer than urban ones. A similar analysis is also performed to obtain bidimensional child poverty orderings between Cameroon and Madagascar and between Colombia and the Dominican Republic. In the first case, the authors do not find evidence of robust poverty dominance, but in the other case they find some evidence suggesting that child poverty was robustly lower in Colombia than in the Dominican Republic. An evaluation of the evolution of tridimensional child poverty in Ghana between 1993 and 1998 is also provided using data on the survival probability of the children, their height-for-age z-score (stunting) and an index of their household's assets. In this case, the authors do not obtain robust poverty dominance results.

Another reference on multidimensional poverty orderings is Crawford (2005), who suggests a different approach for testing first, second and third-order dominance based on a multidimensional extension of the Goodness of Fit method proposed by Anderson (1996) for the unidimensional case. This author also provides an application of his test for the bidimensional case, analysing the evolution of the joint distribution of household expenditure and non-labour market time in 
the UK between 1975 and 1995, finding mixed results.

The tests proposed by Duclos et al. (2006) and Crawford (2005) are based on multiple comparisons on a grid of points. Alternatively, McCaig and Yatchew (2007) present a framework for testing multidimensional stochastic dominance over the entire distribution, using bootstrap techniques to obtain critical values. They also provide an empirical application in a bidimensional setting using data on income and leisure hours for individuals in Germany, the UK, and the USA and they find evidence that bidimensional poverty was lower in Germany than in both the UK and USA.

In turn, Anderson (2008) introduces sample weighted tests for multidimensional stochastic dominance that are multivariate extensions of the Kolmogorov-Smirnov two sample test. He applies these tests to analyse the evolution of welfare and inequality in several countries between 1990 and 1999 using data on per capita GNP, GNP growth rate and average life expectancy. The author obtains mixed results, the main finding being that multidimensional stochastic dominance techniques provide substantially different results than unidimensional analyses.

Table 2 provides a summary of the empirical applications mentioned in this section, as well as others that will be discussed in next section.

$<$ insert Table 2 here $>$

Finally, regarding the available software and codes to perform multidimensional poverty dominance we should say that, to the best of our knowledge, the DASP Stata package developed by Araar and Duclos (2013), which allows to perform bidimensional poverty dominance, is the only readily available option so far. 


\subsection{Further issues in multidimensional poverty orderings}

This section is devoted to some further issues related to multidimensional poverty orderings that could be important in some particular settings, namely those dealing with ordinal data and the counting approach.

In the review we have done so far on the relationship between multivariate stochastic dominance conditions and multidimensional poverty orderings, we have assumed that the variables have a cardinal support. However, many of the variables of interest in poverty analyses are ordinal (for example, the health status of individuals). Hence, in those cases it is necessary to extend the results presented so far to deal with ordinal variables. ${ }^{6}$ To the best of our knowledge, there is not any contribution in the literature that explicitly treats the relationship between multivariate stochastic dominance conditions and multidimensional poverty orderings in the presence of ordinal variables. Nonetheless, Yalonetzky (2013) derived multivariate stochastic dominance conditions for establishing welfare orderings when the variables are ordinal. Hence, given that welfare and poverty are closely related concepts, the results provided by Yalonetzky (2013) could be used to provide conditions for multidimensional poverty dominance when working with ordinal variables. These conditions will be the discrete analogues to the conditions of first and second-order dominance previously reviewed in Section 3.2.

Yalonetzky (2013) also proposes a statistical test for stochastic dominance, based on an extension of the nonparametric test of Anderson (1996), both for the bidimensional case and the case of more than two dimensions and provides an empirical application using data from Peru on three ordinal variables representing different dimensions of well-being. The welfare of adults living in Lima is compared against that of adults living in any other part of the country and no evidence of dominance is found when analysing the joint distribution of the three variables.

\footnotetext{
${ }^{6}$ This issue could also apply to the univariate case. However, when analysing unidimensional poverty, the most commonly used variables are continuous, namely income, consumption or wealth. For that reason, in this section we limit the discussion on ordinal variables to the multidimensional case. Nevertheless, Yalonetzky (2012) considers unidimensional poverty orderings determined by stochastic dominance conditions relevant for ordinal variables.
} 
To conclude this section, we briefly discuss some recent attempts to derive dominance conditions for a particular type of multidimensional poverty measures, namely those based on the so-called counting approach. This approach, which was introduced by Atkinson (2003) and has received a growing interest over the last years, consists of counting the number of dimensions in which individuals are deprived and has the advantage of dealing well not only with continuous but also with ordinal and categorical variables. In this context, the contribution of Alkire and Foster (2011) has been particularly influential. These authors propose an identification of the poor based on two steps. First, individuals are identified as deprived or non-deprived in each of the dimensions based on a dimension-specific poverty threshold. After that, they propose to count the number of dimensions in which individuals are deprived and then identify these individuals as poor if the number of deprivations is greater than a certain threshold (usually denoted as $k$ ). To aggregate this information, Alkire and Foster (2011) propose a family of measures (known as the AF family) that are extensions to the multidimensional case of the family of measures proposed by Foster et al. (1984). The AF methodology is simple both conceptually and computationally and because of that it has had a great influence in the literature. Actually, as we said in the Introduction, the MPI adopted by the United Nations is an index of the AF family. Other counting measures can be found in Bossert et al. (2009).

Despite their theoretical and practical appeal, poverty rankings may not be robust to changes in the different parameters of the multidimensional counting poverty indices, such as the identification threshold $(k)$ or the functional form of the index. Consequently, there have been several recent attempts to derive dominance conditions for robust multidimensional poverty orderings based on counting measures. For example, Lasso de la Vega (2010) and Alkire and Foster (2011) derive dominance conditions for robust multidimensional poverty orderings across different values of $k$. Another contribution that is worth pointing out is that of Bennett and Mitra (2013), who propose a general framework to develop dominance tests on counting measures based on the standard p-value approach. This procedure would allow, for example, to infer the specific 
range of poverty lines over which a poverty ordering holds or the specific dimensions in which a country (or region) underperforms, among other questions that can be relevant form a policy perspective. Finally, Yalonetzky (2014) propose the use of stochastic dominance techniques to obtain conditions for robust multidimensional poverty orderings based on popular counting measures. In particular, he derives the conditions that ensure the robustness of multidimensional poverty orderings to any values of the parameters of the counting measures and propose a statistical testing procedure for these conditions. Unlike Lasso de la Vega (2010) and Alkire and Foster (2011), whose methods focus on the variation of the identification threshold $k$, the conditions derived by Yalonetzky (2014) ensure the robustness of poverty orderings to different simultaneous choices of the parameters of the counting measures. Yalonetzky (2014) also applies his testing procedure to analyse multidimensional poverty in Europe using indicators of educational achievement, self-reported health and ability to keep the house warm, finding robust multidimensional poverty orderings between different countries.

\section{Concluding remarks}

The traditional approach to make poverty comparisons has consisted of comparing aggregate indices. However, these indices are based on rules of aggregation and require a number of methodological choices about the form and properties of the index and the poverty line that could affect the robustness of the results. Additionally, in the multidimensional case, most of the indices used do not take appropriately into account the degree of dependence between the dimensions of poverty, missing an important feature of this phenomenon.

To overcome these drawbacks, stochastic dominance techniques have been regarded as valuable tools for obtaining robust poverty orderings both in the unidimensional and in the multidimensional cases. Moreover, in the multidimensional context, stochastic dominance techniques capture the possible relationships between the dimensions of poverty as it relies upon their joint 
distribution. In this paper, first and second-order stochastic dominance conditions have been reviewed in both cases. In the univariate case, we have described the dominance conditions that should be fulfilled to obtain robust poverty orderings. It has been observed that firstorder conditions are linked to the comparison of cumulative distribution functions (or quantile functions), whereas second-order conditions are related to comparisons of the areas under these functions.

In the multivariate case, we have also described the dominance conditions that should be fulfilled to obtain robust poverty orderings. In this context, the application of stochastic dominance techniques poses additional difficulties, as the relationship between dominance conditions and poverty orderings depends on the type of relationship between the dimensions considered. In the bivariate case, it is shown that for first-order conditions, comparisons of joint cumulative distribution and survival functions should be made. Moreover, it has been emphasized that when the two dimensions are regarded as substitutes (complementary), dominance conditions are related to the intersection (union) approach to measure poverty. For second-order conditions, the comparison is made between volumes below and above joint cumulative distribution and joint survival functions. A discussion on the additional challenges that the problem of poverty comparisons with more than two dimensions entails, both from the theoretical and empirical point of view, is also included. The problems of dealing with ordinal data and those faced when using multidimensional poverty measures based on counting approach have also been briefly described.

Both in the univariate and multivariate settings, some tests for stochastic dominance have been reviewed, including those based on the comparison of distributions over a set of grid points and those based on the Kolmogorov-Smirnov test. Also, some empirical applications of these tests have been discussed. In all cases, an important emphasis has been put in the weaknesses and strengths of the methodologies applied. 


\section{Acknowledgements}

We thank the referees for their helpful comments and suggestions that have improved the paper. The financial support from Spanish Ministry of Economy and Competitiveness (Project ECO2016-77900-P) and ERDF is acknowledged. The second author also acknowledges financial support from Junta de Castilla y León-Consejería de Educación (Project VA148G18). The third author also acknowledges financial support from Autonomous Community of Madrid and European Commission (Project S2015/HUM-3416-DEPOPOR-CM). The usual disclaimers apply.

\section{References}

Aaberge, R. and Brandolini, A. (2015). Multidimensional poverty and inequality. In Atkinson, A. and Bourguignon, F., editors, Handbook of Income Distribution, pages 141-216. ElsevierNorth Holland.

Ahamdanech, I., Pérez, C. G., and Prieto-Alaiz, M. (2010). Convergence of spanish regions, 1990-2003. a new approach using stochastic dominance techniques. Journal of Income Distribution, 19(1):33-47.

Alkire, S. and Foster, J. E. (2011). Counting and multidimensional poverty measurement. Journal of Public Economics, 95(7-8):476-487.

Alkire, S., Foster, J. E., Seth, S., Santos, M. E., Roche, J. M., and Ballon, P. (2015). Multidimensional poverty measurement and analysis. Oxford University Press.

Álvarez-Esteban, P. C., del Barrio, E., Cuesta-Albertos, J. A., and Matrán, C. (2016). A contamination model for the stochastic order. TEST, 25(4):751-774.

Álvarez-Esteban, P. C., del Barrio, E., Cuesta-Albertos, J. A., and Matrán, C. (2017). Models 
for the assessment of treatment improvement: The ideal and the feasible. Statistical Science, 32(3):469-485.

Anderson, G. (1996). Nonparametric tests of stochastic dominance in income distributions. Econometrica, 64(5):1183-1193.

Anderson, G. (2008). The empirical assessment of multidimensional welfare, inequality and poverty: Sample weighted multivariate generalizations of the Kolmogorov-Smirnov two sample tests for stochastic dominance. Journal of Economic Inequality, 6(1):73-87.

Araar, A. and Duclos, J.-Y. (2013). User Manual for Stata Package DASP: Version 2.3. PEP, World Bank, UNDP and University of Laval.

Atkinson, A. B. (1970). On the measurement of inequality. Journal of Economic Theory, $2(3): 244-263$.

Atkinson, A. B. (1987). On the measurement of poverty. Econometrica, 55(4):749-764.

Atkinson, A. B. (2003). Multidimensional deprivation: Contrasting social welfare and counting approaches. Journal of Economic Inequality, 1(1):51-65.

Atkinson, A. B. and Bourguignon, F. (1982). The comparison of multi-dimensioned distributions of economic status. The Review of Economic Studies, 49(2):183-201.

Barrett, G. F. and Donald, S. G. (2003). Consistent tests for stochastic dominance. Econometrica, 71(1):71-104.

Bawa, V. S. (1978). Safety-first, stochastic dominance, and optimal portfolio choice. Journal of Financial and Quantitative Analysis, 13(2):255-271.

Bawa, V. S. (1982). Stochastic dominance: A research bibliography. Management Science, 28(6):698-712. 
Bennett, C. J. (2008). New consistent integral-type tests for stochastic dominance. Mimeo, Vanderbilt University.

Bennett, C. J. (2013). Inference for dominance relations. International Economic Review, 54(4):1309-1328.

Bennett, C. J. and Mitra, S. (2013). Multidimensional poverty: Measurement, estimation, and inference. Econometric Reviews, 32(1):57-83.

Berihuete, A., Ramos, C. D., and Sordo, M. A. (2018). Welfare, inequality and poverty analysis with rtip: An approach based on stochastic dominance. The R Journal, 10(1):328 - 341 .

Bishop, J., Chakraborti, S., and Thistle, P. (1989). Asymptotically distribution-free statistical inference for generalized Lorenz curves. The Review of Economics and Statistics, 71(4):725727.

Bishop, J., Formby, J., and Thistle, P. (1992). Convergence of the south and non-south income distributions, 1969-1979. The American Economic Review, 82(1):262-272.

Bossert, W., Chakravarty, S. R., and D'Ambrosio, C. (2009). Multidimensional poverty and material deprivation. Working Papers 129, ECINEQ, Society for the Study of Economic Inequality.

Bourguignon, F. and Chakravarty, S. (2003). The measurement of multidimensional poverty. Journal of Economic Inequality, 1(1):25-49.

Chakravarty, S. R. (1983). Ethically flexible measures of poverty. The Canadian Journal of Economics / Revue canadienne d'Economique, 16(1):74-85.

Clark, S., Hemming, R., and Ulph, D. (1981). On indices for the measurement of poverty. The Economic Journal, 91(362):515-526. 
Crawford, I. (2005). A nonparametric test of stochastic dominance in multivariate distributions. University of Surrey, Institute for Fiscal Studies.

Davidson, R. and Duclos, J.-Y. (2000). Statistical inference for stochastic dominance and for the measurement of poverty and inequality. Econometrica, 68(6):1435-1464.

Davidson, R. and Duclos, J.-Y. (2013). Testing for restricted stochastic dominance. Econometric Reviews, 32(1):84-125.

Denuit, M. and Eeckhoudt, L. (2010). Bivariate stochastic dominance and substitute risk(in)dependent utilities. Decision Analysis, 7(3):302-312.

Donaldson, D. and Weymark, J. A. (1986). Properties of fixed-population poverty indices. International Economic Review, 27(3):667.

Duclos, J.-Y., Sahn, D. E., and Younger, S. D. (2006). Robust multidimensional poverty comparisons. Economic Journal, 116(514):943-968.

Duclos, J.-Y. and Tiberti, L. (2016). Multidimensional poverty indicesa critical assessment. In Adler, M. D. and Fleurbaey, M., editors, The Oxford Handbook of Well-Being and Public Policy. Oxford University Press, Oxford.

Ferreira, F. H. G. and Lugo, M. A. (2013). Multidimensional poverty analysis: Looking for a middle ground. World Bank Research Observer, 28(2):220-235.

Foster, J. E., Greer, J., and Thorbecke, E. (1984). A class of decomposable poverty measures. Econometrica, 52(3):761-766.

Foster, J. E. and Shorrocks, A. F. (1988). Poverty orderings. Econometrica, 56(1):173-177.

Gal, S., Landsberger, M., and Levykson, B. (1981). A compound strategy for search in the labor market. International Economic Review, 22(3):597-608. 
Hadar, J. and Russell, W. (1969). Rules for ordering uncertain prospects. The American Economic Review, 59(1):25-34.

Hanoch, G. and Levy, H. (1969). The efficiency analysis of choices involving risk. The Review of Economic Studies, 36(3):335-346.

Kannai, Y. (1980). The ALEP definition of complementarity and least concave utility functions. Journal of Economic Theory, 22(1):115 - 117.

Kaur, A., Prakasa Rao, B., and Singh, H. (1994). Testing for second-order stochastic dominance of two distributions. Econometric Theory, 10(5):849-866.

Klecan, L., McFadden, R., and McFadden, D. (1991). A robust test for stochastic dominance. Mimeo, MIT.

Kolm, S.-C. (1977). Multidimensional egalitarianisms. The Quarterly Journal of Economics, 91(1):1-13.

Lasso de la Vega, M. C. (2010). Counting poverty orderings and deprivation curves. In Bishop, J. A., editor, Studies in Applied Welfare Analysis: Papers from the Third ECINEQ Meeting, pages 153-172. Emerald.

Lean, H.-H., Wong, W.-K., and Zhang, X. (2008). The sizes and powers of some stochastic dominance tests: A monte carlo study for correlated and heteroskedastic distributions. Mathematics and Computers in Simulation, 79(1):30-48.

Lehmann, E. L. (1955). Ordered families of distributions. The Annals of Mathematical Statistics, 26(3):399-419.

Leland, H. E. (1972). Theory of the firm facing uncertain demand. The American Economic Review, 62(3):278-291. 
Levy, H. (1992). Stochastic dominance and expected utility: Survey and analysis. Management Science, 38(4):555-593.

Levy, H. and Paroush, J. (1974). Multi-period stochastic dominance. Management Science, 21(4):428-435.

Linton, O., Maasoumi, E., and Whang, Y.-J. (2005). Consistent testing for stochastic dominance under general sampling schemes. Review of Economic Studies, 72(3):735-765.

Linton, O., Song, K., and Whang, Y.-J. (2010). An improved bootstrap test of stochastic dominance. Journal of Econometrics, 154(2):186-202.

Maasoumi, E. (2001). Parametric and nonparametric tests of limited domain and ordered hypotheses in economics. In Baltagi, B., editor, A Companion to Theoretical Econometrics, pages 538-556. Blackwell Publishing Ltd, Malden, MA, USA.

Maasoumi, E. and Heshmati, A. (2000). Stochastic dominance amongst swedish income distributions. Econometric Reviews, 19(3):287-320.

Maasoumi, E. and Heshmati, A. (2005). Evaluating dominance ranking of PSID incomes by various household attributes. In Betti, G. and Lemmi, A., editors, Advances on Income Inequality and Concentration Measures, pages 47-69. Taylor \& Francis, London.

Madden, D. and Smith, F. (2000). Poverty in Ireland, 1987-1994: A stochastic dominance approach. The Economic and Social Review, 31(3):187-214.

McCaig, B. and Yatchew, A. (2007). International welfare comparisons and nonparametric testing of multivariate stochastic dominance. Journal of Applied Econometrics, 22(5):951969.

McFadden, D. (1989). Testing for stochastic dominance. In Fomby, T. and Seo, T., editors, Studies in the Economics of Uncertainty, pages 113-134. Springer, New York. 
Moberg, E. A. and Solow, A. R. (2015). Stochastic dominance test (MATLAB and R code). Woods Hole Open Access Server, Woods Hole, MA.

Mosler, K. and Scarsini, M. (1991). Some theory of stochastic dominance. In Mosler, K. and Scarsini, M., editors, Stochastic Orders and Decision Under Risk. (IMS Lecture NotesMonograph Series), volume 19, pages 261-284. Institute of Mathematical Statistics.

O'Brien, G. L. and Scarsini, M. (1991). Multivariate stochastic dominance and moments. Mathematics of Operations Research, 16(2):382-389.

Ravallion, M. (1992). Poverty comparisons: A guide to concepts and methods. Living Standards Measurement Study Working Paper 88. Washington DC World Bank.

Rothschild, M. and Stiglitz, J. E. (1973). Some further results on the measurement of inequality. Journal of Economic Theory, 6(2):188-204.

Saposnik, R. (1981). Rank-dominance in income distributions. Public Choice, 36(1):147-151.

Sen, A. (1985). Commodities and Capabilities. North-Holland, Amsterdam.

Shorrocks, A. F. (1983). Ranking income distributions. Economica, 50(197):3-17.

Sriboonchitta, S., Wong, W.-K., and Nguyen, H. T. (2010). Stochastic Dominance and Applications to Finance, Risk and Economics. CRC Press, Boca Raton, Florida.

Stiglitz, J. E., Sen, A., and Fitoussi, J.-P. (2009). Report by the commission on the measurement of economic performance and social progress.

Thon, D. (1979). On measuring poverty. Review of Income and Wealth, 25(4):429-439.

Tse, Y. and Zhang, X. (2004). A Monte Carlo investigation of some tests for stochastic dominance. Journal of Statistical Computation and Simulation, 74(5):361-378. 
Watts, H. (1968). An economic definition of poverty. In Moynihan, D., editor, On Understanding Poverty, pages 316-329. Basic Books, New York.

Whitmore, G. A. (1970). Third-degree stochastic dominance. The American Economic Review, 60(3):457-459.

Xu, K. (1997). Asymptotically distribution-free statistical test for generalized lorenz curves: An alternative approach. Journal of Income Distribution, 7(1):45 - 62.

Yalonetzky, G. (2012). Poverty measurement with ordinal variables: A generalisation of a recent contribution. ECINEQ WP 2012-246.

Yalonetzky, G. (2013). Stochastic dominance with ordinal variables: Conditions and a test. Econometric Reviews, 32(1):126-163.

Yalonetzky, G. (2014). Conditions for the most robust multidimensional poverty comparisons using counting measures and ordinal variables. Social Choice and Welfare, 43(4):773-807.

Zheng, B. (1997). Aggregate poverty measures. Journal of Economic Surveys, 11(2):123-162.

Zheng, B. (1999). On the power of poverty orderings. Social Choice and Welfare, 16(3):349-371.

Zheng, B. (2000). Poverty orderings. Journal of Economic Surveys, 14(4):427-466. 


\begin{tabular}{|c|c|c|c|c|}
\hline Paper & Method & Scope & Data Sources & Main findings \\
\hline $\begin{array}{l}\text { Bishop } \\
\text { et al. } \\
(1992)\end{array}$ & $\begin{array}{l}\text { Comparison } \\
\text { over a set } \\
\text { of grid } \\
\text { points }\end{array}$ & US (1970s) & $\begin{array}{l}\text { Census of Popu- } \\
\text { lation and Hous- } \\
\text { ing }\end{array}$ & $\begin{array}{l}\text { Convergence between } \\
\text { the South and non- } \\
\text { South over the } 70 \mathrm{~s}\end{array}$ \\
\hline $\begin{array}{l}\text { Madden } \\
\text { and Smith } \\
(2000)\end{array}$ & $\begin{array}{l}\text { Comparison } \\
\text { over a set } \\
\text { of grid } \\
\text { points }\end{array}$ & $\begin{array}{l}\text { Ireland } \\
1994)\end{array}$ & $\begin{array}{l}\text { Irish Household } \\
\text { Budget Survey }\end{array}$ & $\begin{array}{llr}\text { Decrease in poverty } \\
\text { between } 1987 \text { and } \\
1994\end{array}$ \\
\hline $\begin{array}{l}\text { Ahamdanech } \\
\text { et al. } \\
(2010)\end{array}$ & $\begin{array}{l}\text { Comparison } \\
\text { over a set } \\
\text { of grid } \\
\text { points }\end{array}$ & $\begin{array}{l}\text { Spain } \\
2003)\end{array}$ & $\begin{array}{ll}\text { Spanish } & \text { House- } \\
\text { hold } & \text { Budget } \\
\text { Survey } & \end{array}$ & $\begin{array}{l}\text { No significant conver- } \\
\text { gence between Span- } \\
\text { ish regions }\end{array}$ \\
\hline $\begin{array}{l}\text { Davidson } \\
\text { and Duclos } \\
(2000)\end{array}$ & $\begin{array}{l}\text { Comparison } \\
\text { over a set } \\
\text { of grid } \\
\text { points }\end{array}$ & $\begin{array}{l}\text { US, Canada and } \\
\text { the Netherlands } \\
(1991)\end{array}$ & $\begin{array}{l}\text { Luxembourg } \\
\text { Income Study } \\
\text { (LIS) }\end{array}$ & $\begin{array}{l}\text { Dominance of Canada } \\
\text { and the Netherlands } \\
\text { over US }\end{array}$ \\
\hline $\begin{array}{l}\text { Davidson } \\
\text { and Duclos } \\
(2013)\end{array}$ & $\begin{array}{l}\text { Comparison } \\
\text { over a set } \\
\text { of grid } \\
\text { points }\end{array}$ & $\begin{array}{l}\text { US, the Nether- } \\
\text { lands, UK, } \\
\text { Germany } \\
\text { and Ireland } \\
(1999 / 2000)\end{array}$ & $\begin{array}{l}\text { Luxembourg } \\
\text { Income Study } \\
\text { (LIS) }\end{array}$ & Mixed results \\
\hline $\begin{array}{l}\text { Maasoumi } \\
\text { and Hesh- } \\
\text { mati } \\
(2000)\end{array}$ & $\begin{array}{l}\text { K-S-based } \\
\text { test with } \\
\text { bootstrap }\end{array}$ & $\begin{array}{l}\text { Sweden } \\
1990)\end{array}$ & $\begin{array}{l}\text { Swedish Income } \\
\text { Panel }\end{array}$ & $\begin{array}{l}\text { Redistributive and } \\
\text { welfare policies favour } \\
\text { the elderly, females } \\
\text { and large households }\end{array}$ \\
\hline $\begin{array}{l}\text { Maasoumi } \\
\text { and Hesh- } \\
\text { mati } \\
(2005)\end{array}$ & $\begin{array}{l}\text { K-S-based } \\
\text { test with } \\
\text { bootstrap }\end{array}$ & US (1968-1997) & PSID & $\begin{array}{l}\text { Dominance of more re- } \\
\text { cent distributions over } \\
\text { earlier ones }\end{array}$ \\
\hline
\end{tabular}

Table 1: Empirical studies of univariate stochastic dominance 


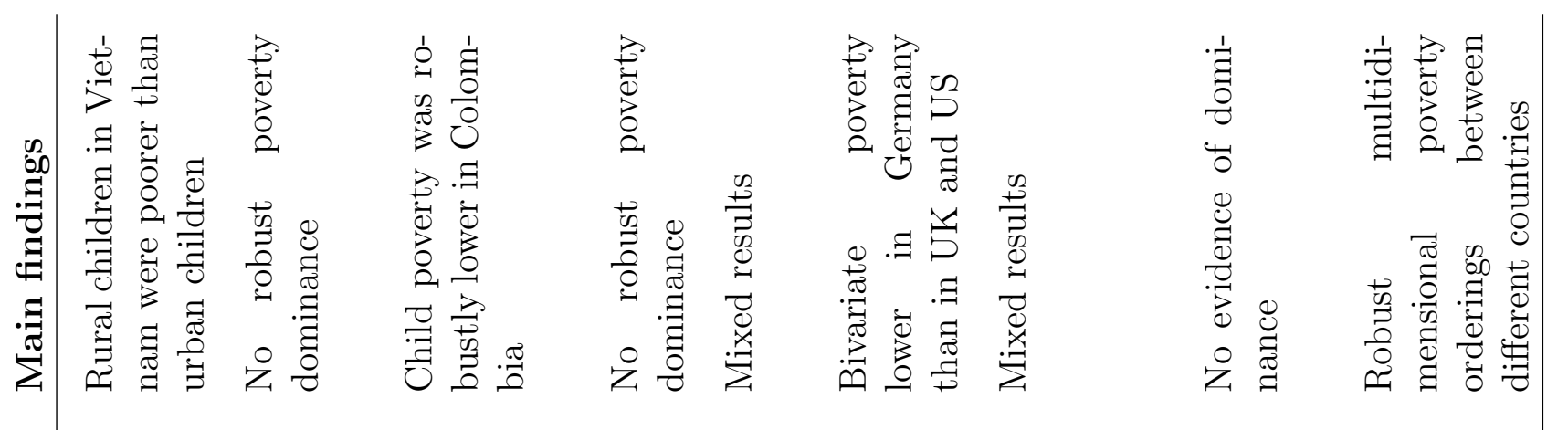

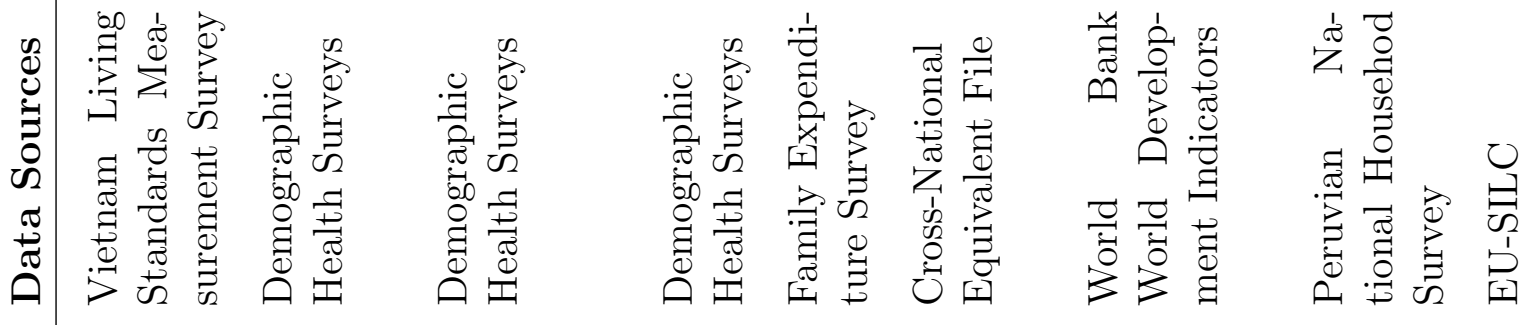

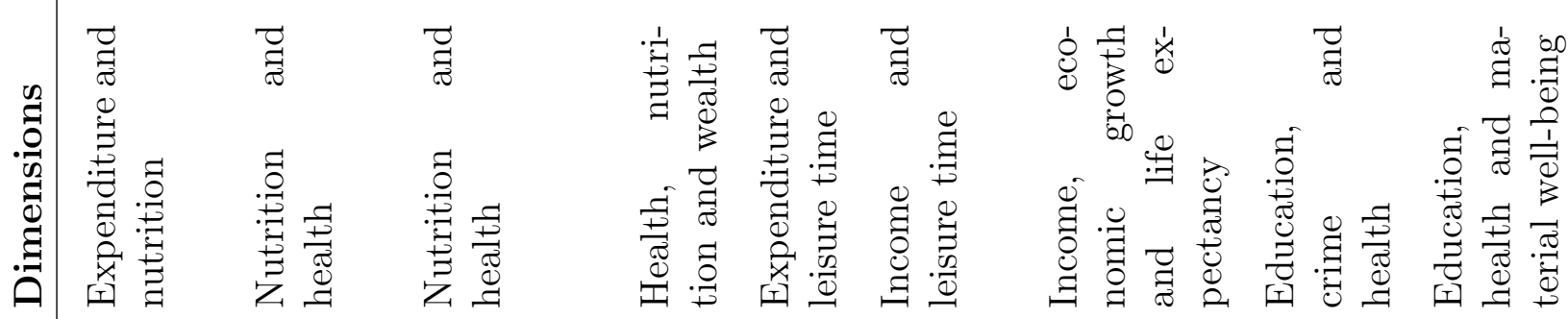

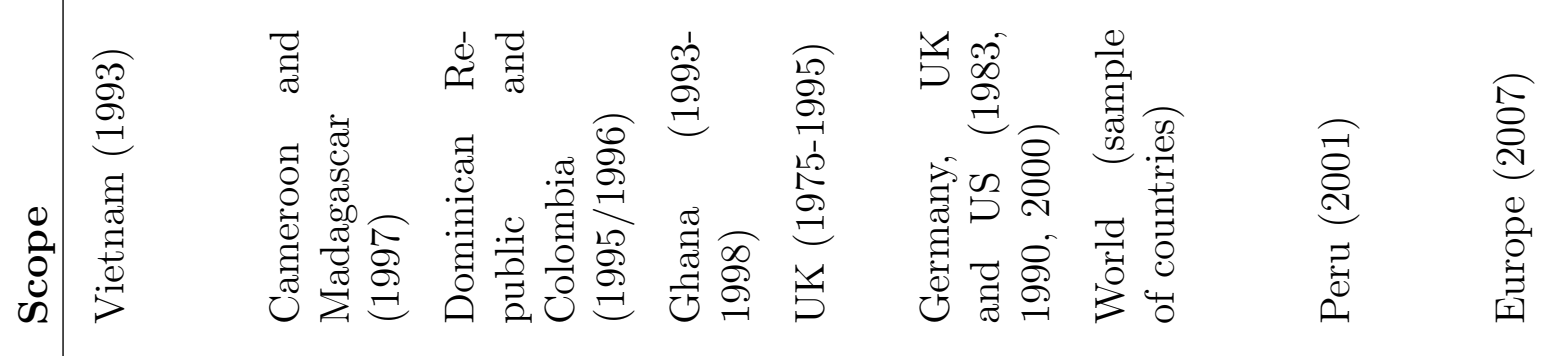

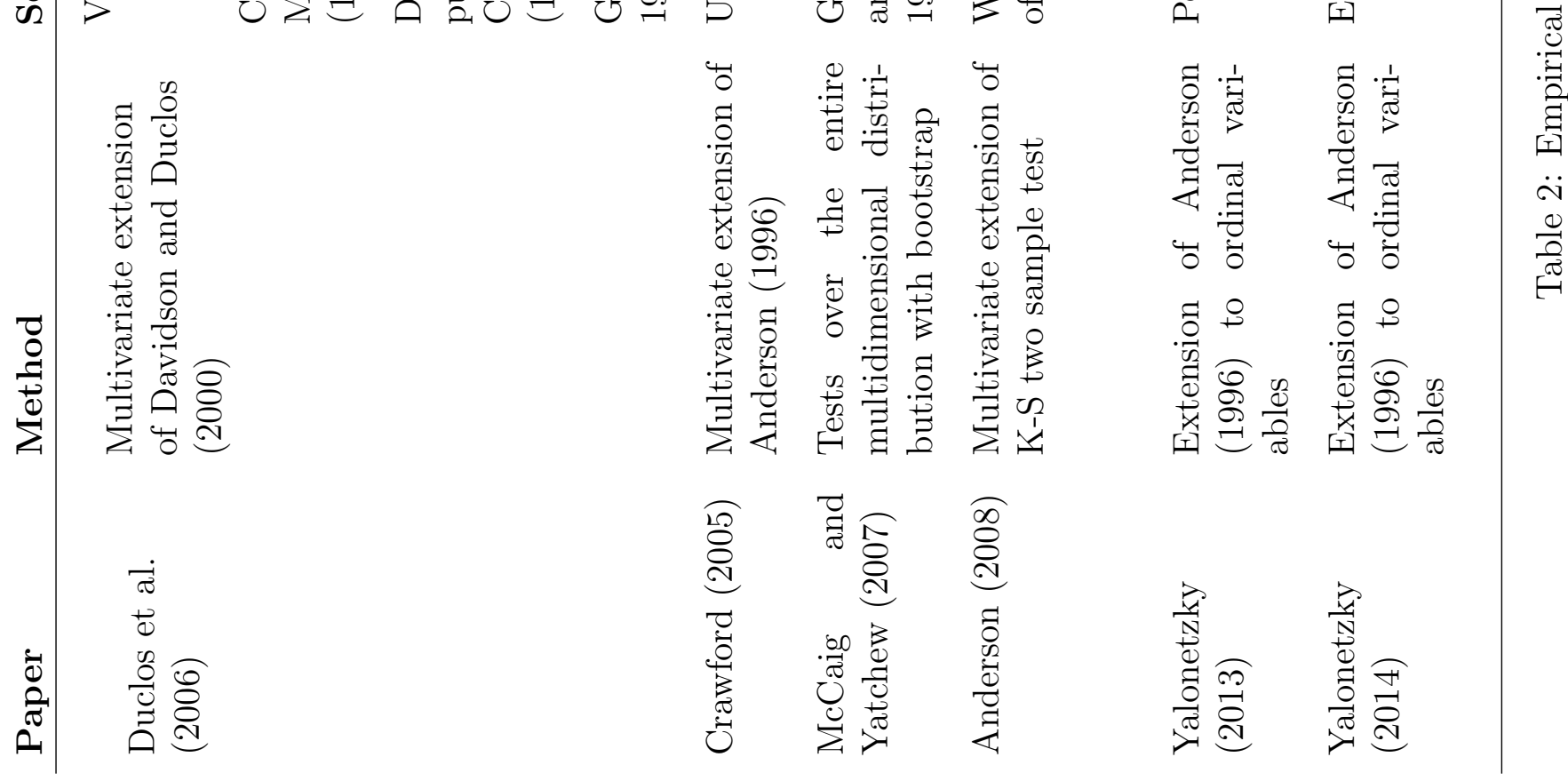



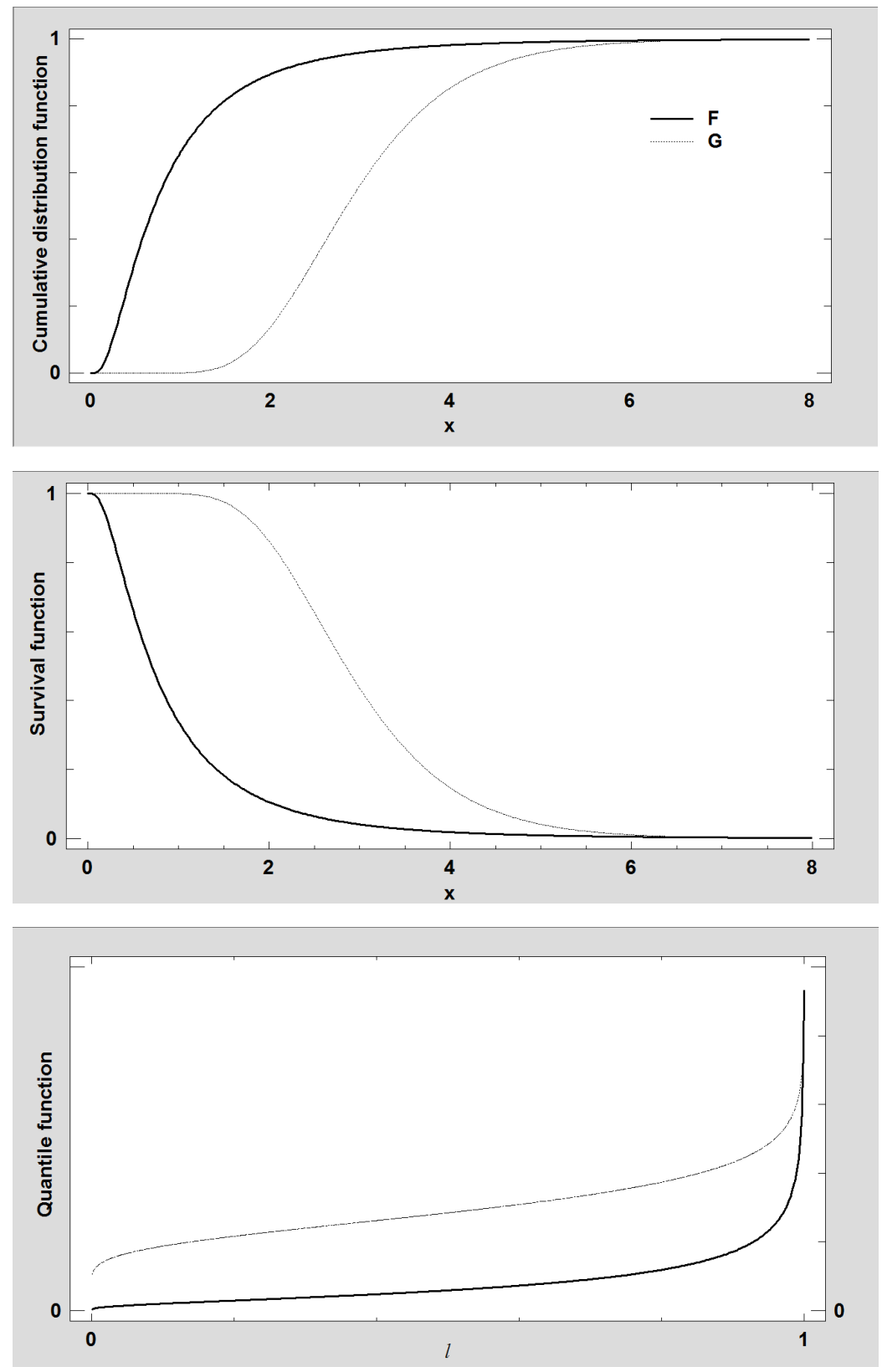

Figure 1: First-order stochastic dominance of G over F 

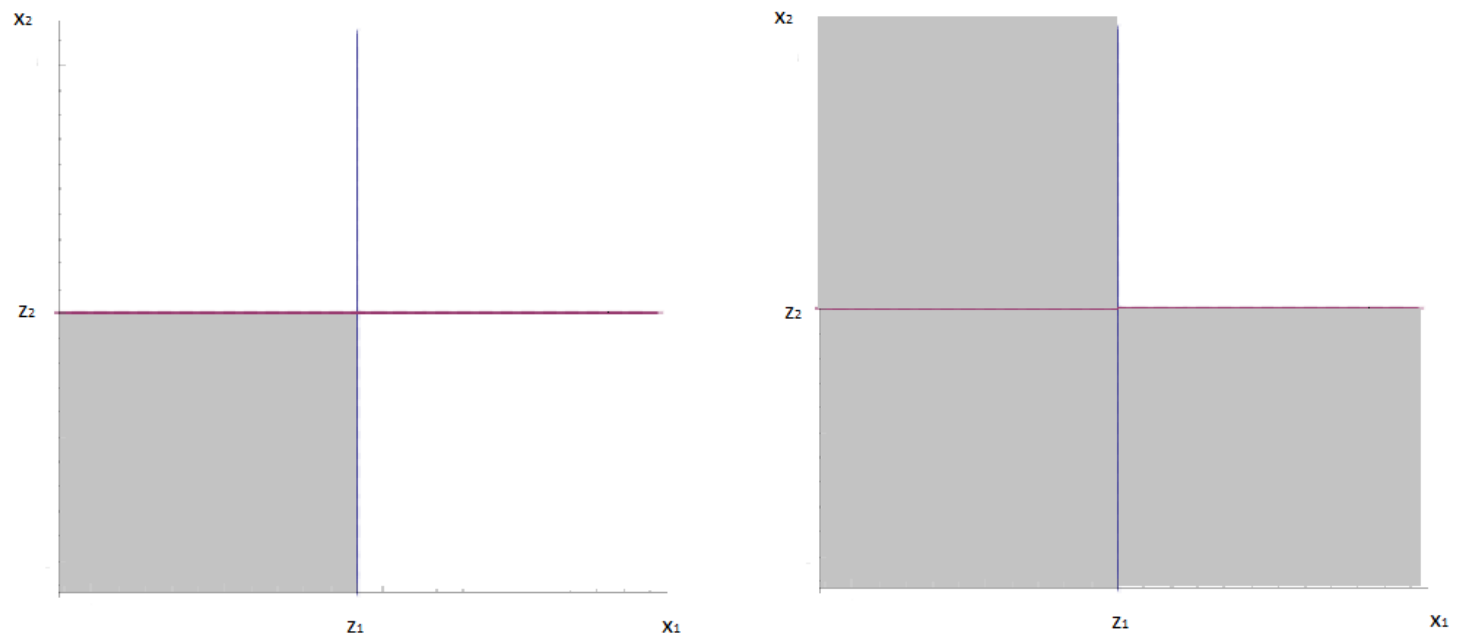

Figure 2: Intersection (left panel) and union (right panel) approaches to poverty measurement. 